\title{
Nano-vectors for efficient liver specific gene transfer
}

\author{
Atul Pathak' \\ Suresh PVyas ${ }^{2}$ \\ Kailash C Gupta' \\ 'Nucleic Acids Research Laboratory, \\ Institute of Genomics and Integrative \\ Biology, Delhi University Campus, \\ Delhi, India ${ }^{2}$ Department of \\ Pharmaceutical Sciences, Dr. Harisingh \\ Gour Vishwavidyalaya, Sagar, (M.P.), \\ India
}

\begin{abstract}
Recent progress in nanotechnology has triggered the site specific drug/gene delivery research and gained wide acknowledgment in contemporary DNA therapeutics. Amongst various organs, liver plays a crucial role in various body functions and in addition, the site is a primary location of metastatic tumor growth. In past few years, a plethora of nano-vectors have been developed and investigated to target liver associated cells through receptor mediated endocytosis. This emerging paradigm in cellular drug/gene delivery provides promising approach to eradicate genetic as well as acquired diseases affecting the liver. The present review provides a comprehensive overview of potential of various delivery systems, viz., lipoplexes, liposomes, polyplexes, nanoparticles and so forth to selectively relocate foreign therapeutic DNA into liver specific cell type via the receptor mediated endocytosis. Various receptors like asialoglycoprotein receptors (ASGP-R) provide unique opportunity to target liver parenchymal cells. The results obtained so far reveal tremendous promise and offer enormous options to develop novel DNAbased pharmaceuticals for liver disorders in near future.
\end{abstract}

Keywords: hepatocytes, nanoparticles, liposomes, nucleic acids, asialoglycoprotein receptors

\section{Introduction}

The prospects of gene therapy on the future of modern molecular medicine hold a great promise for alleviation or cure from many untreatable diseases. However, the lack of efficient site specific delivery systems obscured the introduction of gene medicine in clinical practice and therefore, the potential of gene therapy has not been realized completely. Ideally, a gene delivery system should be stable, biocompatible, nontoxic, cost effective and capable to transfer exogenous highly anionic genetic materials (ie, DNAs, antisense oligonucleotides [AS-ODNs], short interfering RNAs [siRNAs]) into tissue specific site. Viral vectors (ie, adenovirus, retrovirus) have been extensively investigated and demonstrated efficient hepatocytes transfection efficiency even relevant to clinically acceptable level (Wu et al 1998). Their clinical applications are hindered due to safety considerations (Crystal 1995; Felgner et al 1997; Hacein-BeyAbina et al 2003). Moreover, last three decades have seen tremendous developments in various nonviral synthetic delivery systems like liposomes, nanoparticles, lipoplexes and polyplexes for genes and oligonucleotides (ODNs) A number of cationic polymers have also been reported to execute efficient gene transfection including polyethylenimine (PEI), polyallylamine (PAA), poly-L-lysine (PLL), chitosan, etc (Elouahabi and Ruysschaert 2005; Park et al 2006; Pathak et al 2007).

A major goal of gene therapy is to obtain targeted vectors that transfer genes efficiently to specific cell types. The liver possesses a variety of characteristics (its large size, central role in metabolism, accessibility to large molecules and secretion of serum proteins) that make this organ very attractive for gene therapy. The liver plays a pivotal role in the metabolism and more importantly as protein factory for serum circulating polypeptides (ie, coagulation factors) and various enzymes. Being a very 
large organ (cells in humans), the liver serves as a major protein and lipid cell production site. At the same time, it is a partial "immuno-privilege" site that tolerates all potential immunological reactions against gastrointestinal tract (GIT) invaders entering it through the portal system. Mainly, liver is composed of various cell types including hepatocytes (liver parenchymal cells), sinusoidal endothelial cells and kuffer cells (resident liver macrophages). Hepatocytes are the predominant cell type in the liver. In many of the genetic disorders such as ornithine transcarbamylase deficiency, hepatocytes are the prime target to transfer genes. Approximately, $80 \%$ of the liver mass is made of these cells. The hepatocytes are round in shape containing a nucleus and an abundance of cellular organelles (ie, endoplasmic reticulum and golgi apparatus) associated with metabolic and secretary functions. Also there are high numbers of mitochondria to provide energy to support the many metabolic functions of liver. Some of the hepatocytes lie adjacent to endothelial cells, which form the walls of the sinusoids. These two cell types are separated by small space called the space of Disse (Figure 1). The liver is blood rich organ, and its role is coupled with circulating blood (ie, distribution of gene products from liver to systemic circulation). This makes parenchymal liver cells the attractive proposition for gene delivery and thus for the treatment of variety of liver associated diseases (ie, Wilson's disease, hereditary hemochromatosis, $\alpha 1$-antitrypsin deficiency). For instance, genetic defects of hepatocytes also play vital role in $\alpha 1$ antitrypsin deficiency, hemophilia and lipoprotein receptor deficiency (Wu et al 1998). Hepatocellular carcinoma (HCC) is the most common primary liver malignancy with a rising incidence worldwide. In addition to primary tumors, the liver is the most common organ where tumor metastases occur. Both unresectable HCC and liver metastases of digestive tumors lack effective therapy and new therapeutic modalities are needed. Hepatocytes uniquely express asialoglycoprotein receptors (ASGP-R) on their sinusoidal surface and therefore, asialoglycoproteins or galactosylated polymers have been used to deliver variety of pharmaceutical agents (ie, antitumor drugs, genes). This review focuses on various facets and motifs associated with ASGP-R mediated gene delivery to target liver hepatocytes.

\section{Asialoglycoprotein or galactose- specific receptors as molecular porch}

Targeting to liver parenchymal cells is feasible due to the abundance of ASGP-R or hepatic lectins on parenchymal

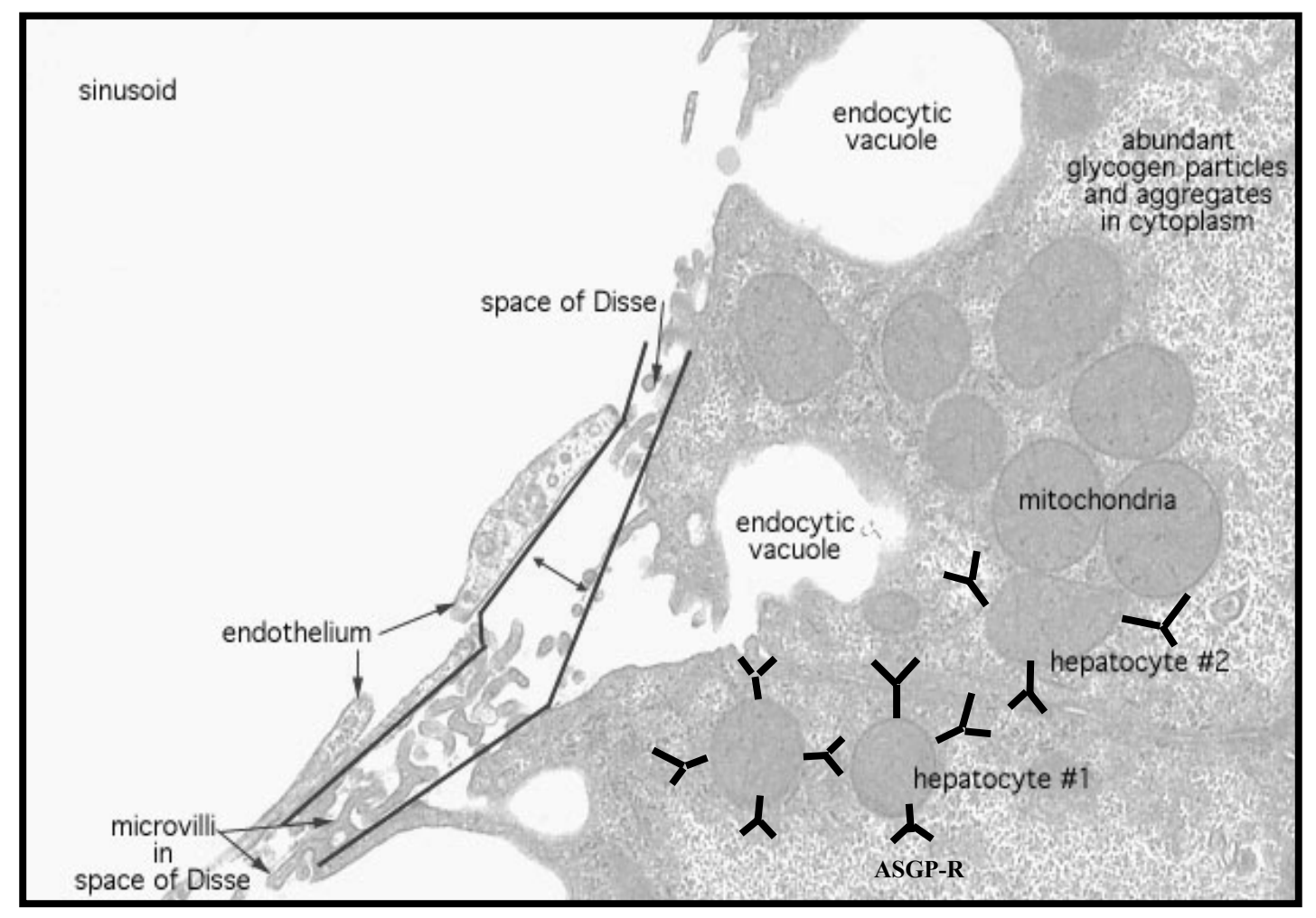

Figure I Schematic representation of hepatocytes. 
hepatocytes (Stockert 1995), which contain $10^{5}-5 \times 10^{5}$ binding sites per cell. These surface receptors are randomly distributed over the sinusoidal (basolateral) plasma membrane domain facing the capillaries and are found in coated pits and uncoated vesicles together with the mannose-6-phosphate, transferrin and poly(Ig) receptors, but they are essentially absent from the apical membrane facing the bile canaliculi (Wall and Hubbard 1981; Geuze et al 1982; Matsuura et al 1982). The human ASGP-R contains two subunits, H1 and H2. The human ASGP-Rs are hetero-oligomeric complexes consisting of $\mathrm{H} 1$ and $\mathrm{H} 2$ subunits in the ratio of 5:1. The major subunit, H1, exclusively contains the signal for endocytosis, while $\mathrm{H} 2$ contributes an important element to basolateral sorting of the hetero-oligomeric receptor molecules (Fuhrer et al 1994). Further, ASGP-R may play a role in the pathogenesis of autoimmune chronic liver diseases.

Naturally, ASGP-R is a prototype of the class of receptors that constitutively enters the cells by recognizing glycoproteins bearing terminal galactose or $\mathrm{N}$-acetyl glucosamine residues via clathrin coated pits and delivers ligand to these intracellular compartments (Stockert 1995). This specific uptake mechanism can be activated by coupling appropriate glycoproteins, lactose or galactose to synthetic substances. Extravasation of delivery systems through the vascular walls is a major obstacle in systemic gene delivery. Sinusoidal wall of the liver lacks a basement membrane and possesses a fenestrated $(\sim 100 \mathrm{~nm})$ endothelium. Therefore, for efficient internalization, systems/polyplexes should be small enough to pass through the fenestrae and get into the space of Disse which is in direct contact with hepatocytes. Endogenous glycoproteins, from which sialic acid has been removed by the action of sialidases, bind tightly to the ASGP-R, which are located on hepatocyte plasma membranes. After internalization by adsorptive endocytosis, they are delivered to lysosomes for degradation. Lysosome is always accepted as the end point of the endocytic pathway mediated by ASGP-R, where ligand was degraded to constituent amino acids and sugars. Therefore, receptor-mediated clearance of ASGP-R is an important aspect of the turnover of plasma glycoproteins. They are elevated in serum of patients with hepatic cirrhosis or hepatitis. Therefore, in addition to being a model of receptor-mediated endocytosis, the presence of the receptors on hepatocytes provides a membrane-bound active site for cell-to-cell interactions for selective targeting of foreign genes.

Several ligands like asialo-feutin, asialo-transferrin, asialo-ceruloplasmin, asialo-lactoferrin, asialo-orosomucoid, lac-BSA, hepatoglobulin, antibodies and galactose have been exploited for cell selective transgene expresion both in vivo and in vitro (Nishikawa and Huang 2001; Arangoa et al 2003). Of these ligands, galactose is the most extensively studied ligand that is recognized by ASGP-R on liver hepatocytes.

\section{Delivery strategies}

In order to exhibit effective pharmacologic response, nucleic acid bioactives must enter the cells and achieve the appropriate concentration in the intracellular compartment. Basically, cellular uptake refers to binding of nucleic acid to the phospholipid bilayers membrane and their ingestion by cell (release into cytoplasm or nucleus). After the binding of nucleic acid to cell-surface protein, internalization into endocytic compartment occurs. The phospholipid bilayers represent major impediment to the moments of ions or molecules. The internalization of naked nucleic acid is generally inefficient, because of their negative charge, only few DNA copies actually diffuse in to the similarly negatively charged cell membranes. This electrostatic repulsion lowers the intracellular uptake of DNA, which makes DNA more prone to nuclease attack.

The strategies that have been adopted to improve the uptake of various nucleic acid based therapeutic agents, are microinjection, passive diffusion, endocytosis (ie, receptor mediated endocytosis, fluid phase pinocytosis, adsorptive endocytosis), and artificially enhanced uptake (ie, using delivery vectors like liposomes, micro- or nanoparticles or dendrimers) (Akhtar et al 2000). Endocytosis mechanism falls into two broad classes, phagocytosis (cell eating phenomenon) and pinocytosis (cell drinking phenomenon). In this process, DNA is engulfed, followed by sequential inward folding of the plasma membrane (invagination), enveloping a droplet of extracellular media, pinching off the membrane and formation of an intracellular coated vesicle containing the ingested material (endosome formation). These coated vesicles or endosomes increase their size by fusing with each other by hemolytic fusion. Most endosomes fuse with primary lysosomes (which contains large amount of hydrolytic enzymes) to form secondary lysosomes, which are the final destination of internalized macromolecules targeted for degradation. While the ingested material is rapidly broken down by the lysosomal enzymes, the endocytic membranes are returned to the plasma membrane. Some endosomes bypass the lysosomes, and traverse the cytoplasm (transcytosis). Macromolecules are generally internalize into the cell by endocytosis and this method is limited to only mammalian cells. Pinocytosis, another form of endocytosis, 
involves macropinocytosis $(>1 \mu \mathrm{m})$, clathrin-mediated endocytosis $(\sim 120 \mathrm{~nm})$, caveolin-mediated endocytosis $(\sim 60 \mathrm{~nm})$, and clathrin- and caveolae-dependent endocytosis $(\sim 90 \mathrm{~nm})$. In internalization process, particles are taken up by cells after splitting them into smaller particles. Conner and Schmid (2003) elegantly demonstrated multiple portal of entry into the mammalian cells. Furthermore, various drug delivery technologies (ie, adenovirus, liposome, nanoparticles, etc) have been developed to efficiently transfer therapeutic material inside the cell. The detailed reports on these nano-vectors can be found elsewhere (Azzam and Domb 2004; Elouahabi and Ruysschaert 2005; Park et al 2006). Figure 2 shows schematic representation of receptor mediated endocytosis.

\section{Lipid based devices for hepatocyte specific gene delivery}

Liposomes are considered to be a mainstream gene/drug delivery technology. It is believed that small liposomes with diameters below $100 \mathrm{~nm}$ have relatively easy access to the transendothelially located hepatocytes (presence of numerous open fenestrations in the endothelial lining of the sinusoids, which have an average diameter of approximately $150 \mathrm{~nm}$ ) without using any targeting ligand. However, liposomes with diameters even higher than those of the endothelial fenestrations may gain access to the hepatocytes in large quantities, depending on their lipid compositions. Applying cell-specific targeting technology to liposomes would further improve the gene delivery efficiency and reduce any unexpected side effects. As discussed earlier, various ligands have been investigated for their bio-signaling and bio-sensing potential to target liver parenchymal cells. Galacotose is the most explored ligand for liver specific gene transfer. Liposomes are glycosylated by introducing glycoproteins or synthetic glycolipids. Some reviews discussed the glycosylated liposomes for cell-selective gene delivery in detail (Hasida et al 2001; Kawakami et al 2002; Nishikawa et al 2003). Several research groups have attempted to actively target glycosylated liposomes to the hepatocytes by exploiting the asialoglycoprotein receptors both in vitro and in vivo. Shimada and coworkers (1997) synthesized biodegradable poly(ethyleneglycol) (PEG)coupled galactolipids, in which the galactose moiety was separated from a diacylglyceride lipid interface by a PEG chain of variable lengths (PEG 10/20/40). The system was designed to exploit the anti-opsonic action and the spacer effect of the PEG chains, to improve the exposure of the galactose moiety and to provide an optimal configuration for interactions with the hepatocyte galactose receptors.
The proposed liposomes, Gal-PEG10-Lip, got cleared rapidly from plasma with a half-life $\left(\mathrm{t}_{1 / 2}\right)$ of $30 \mathrm{~min}$. whereas, identical sized and control liposomes without the Gal-PEG10-Lip had a $\mathrm{t}_{1 / 2}$ of approximately $12 \mathrm{~h}$. In this study, they found that the rapid plasma elimination of the Gal-PEG10-Lip liposomes could be attributed entirely to increased uptake by the kuffer cells of liver ( $>90 \%$ of injected dose). Whereas, the uptake by the spleen was found to be decreased ( $<1 \%$ of injected dose). Further, it was observed that a single injection of $\mathrm{N}$-acetylgalactosamine one min prior to administration of Gal-PEG-Lip liposomes reduced the initial rate of plasma clearance to control levels. However, the incorporation of monomethoxypo ly(ethyleneglycol)-distearoylphosphatidylethanolamine (PEG-DSPE) in the Gal-PEG10-Lip liposomes partially reversed the effect of the galactolipid with respect to liver and spleen uptake. Thus, the observation suggests that the ligands recognized by the galactose receptors on the kuffer cells and transfer the content to these cells instead of hepatocytes.

Some novel galactosylated cholesterol derivatives, cholesten-5-yloxy-N-(4-((1-imino-c-b- D-thiogalactosylethyl) amino) butyl) formamide (Gal-C4-Chol) and its ethyl formamide and hexyl formamide analogues (Gal-C2-Chol, Gal-C6-Chol), were synthesized to prepare liposomal gene carriers (Kawakami et al 1998). Systems possess sufficient charge to bind DNA and galactose residue for ASGP-Rs in hepatocyte. Liposomes, consisting of Gal-C4-Chol, 3 $\beta$ [N'N'N'dimethylaminoethane)-carbamoyl] cholesterol (DC-Chol), and dioleoylphosphatidylethanolamine (DOPE) in ratio of 3:3:4, showed higher transfection activity and $\left[{ }^{32} \mathrm{P}\right] \mathrm{DNA}$ uptake than DC-Chol/DOPE (6:4) liposomes in HepG2 cells. These results indicated that the liposome/DNA complexes prepared using novel galactosylated cholesterol derivatives were efficiently recognized by ASGP-Rs and internalized and led to the gene expression. Additionally, the galactosylated cholesterol derivative with a longer spacer showed higher transfection activity.

Kawakami and coworkers (2000) studied galactosylated cationic liposomes containing N-[1-(2,3-dioleyloxy)propyl]N,N,N-trimethylammonium chloride (DOTMA), Gal-C4Chol and Chol to elucidate the in vivo gene transfection in the liver via ASGP-R mediated endocytosis. A markedly higher gene expression in the liver was observed following intraportally injection of plasmid DNA that was complexed with DOTMA: Chol: Gal-C4-Chol (1:0.5:0.5) and DOTMA/ Gal-C4-Chol (1:1) liposomes. Results showed that the effect was one order of magnitude higher than naked DNA and 

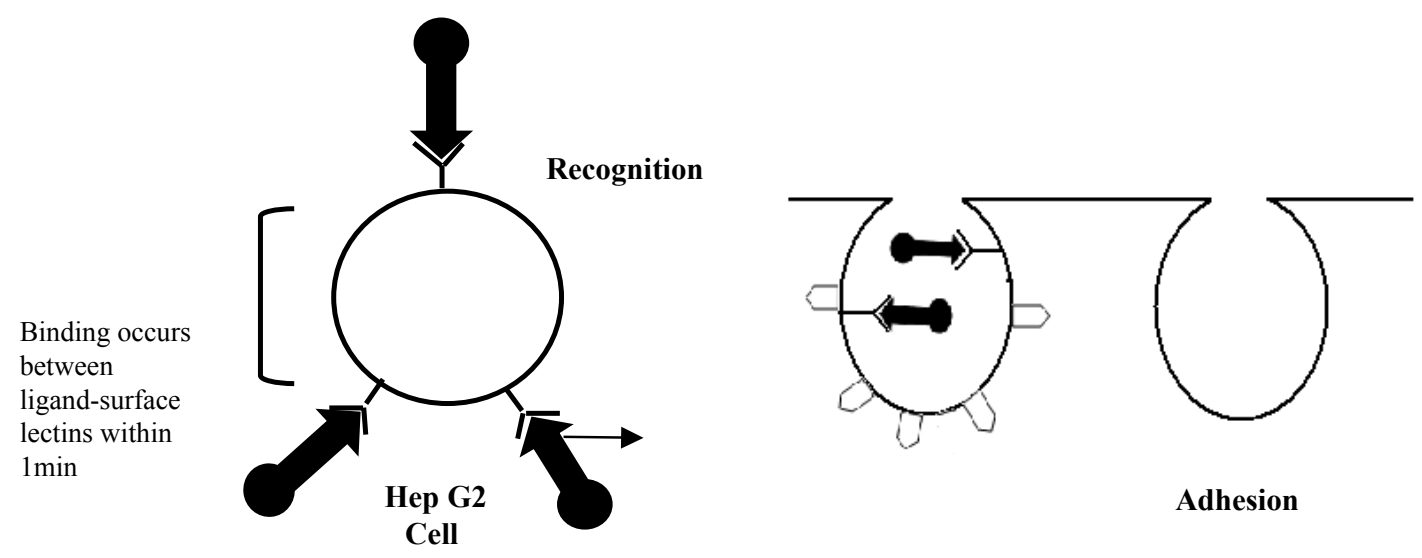

Adhesion

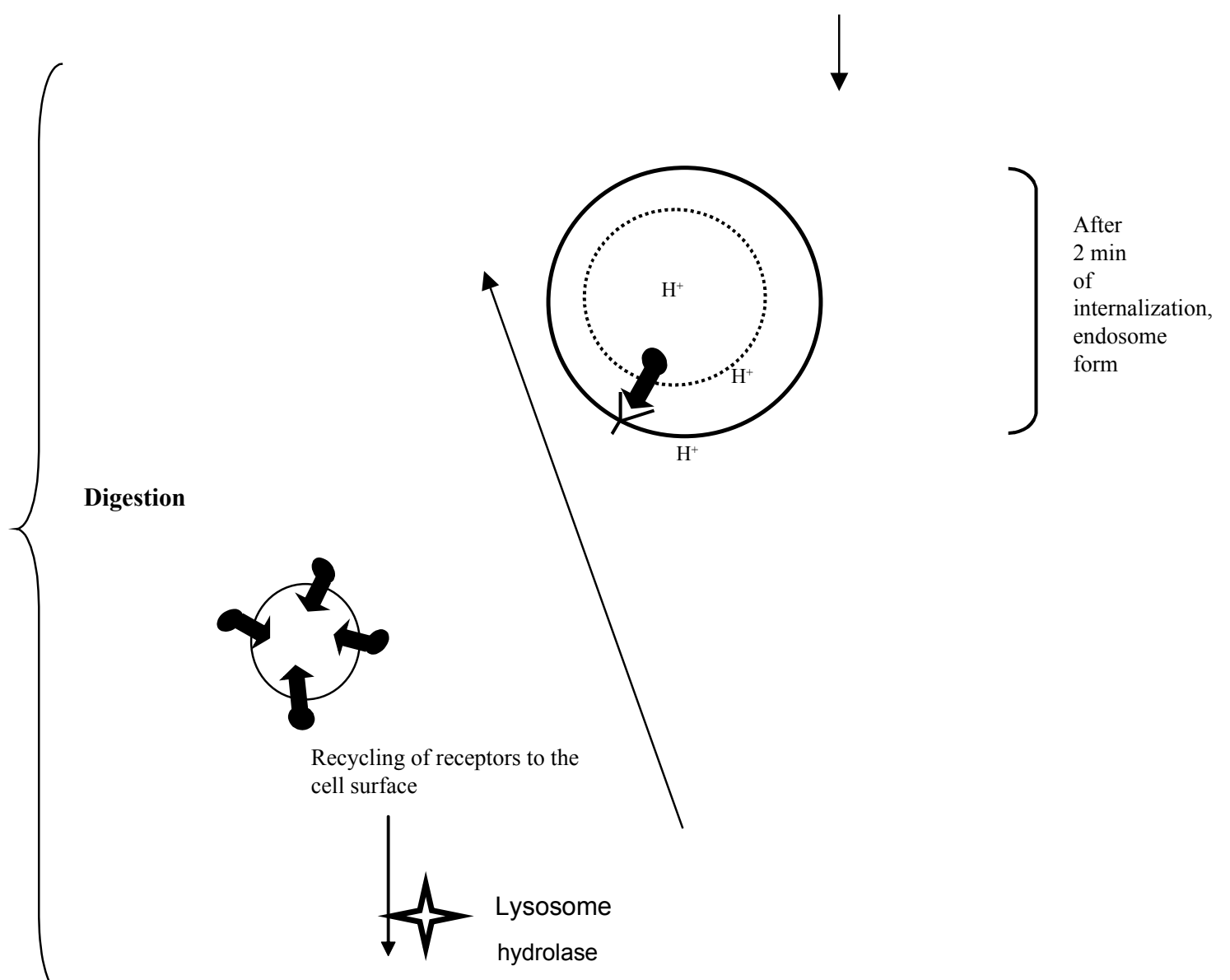

\begin{abstract}
Additional 4 min are
required for ligand

dissociation and
\end{abstract}

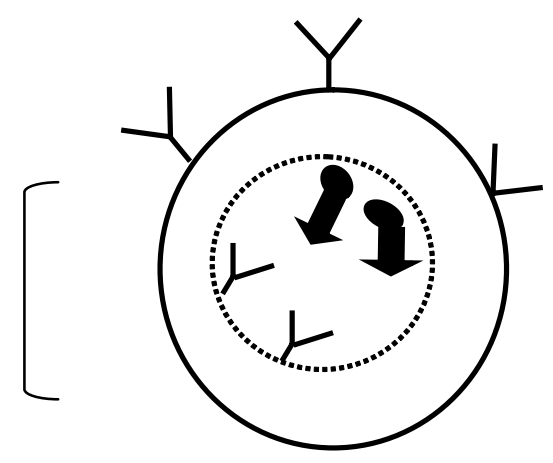

Figure 2 Schematic representation of internalization of ligand anchored system with cell surface lectins. 
DOTMA: Chol (1:1) liposomes. While, prior exposure with galactosylated bovine serum albumin significantly reduced the hepatic gene expression (Figure 3).

Another group of researchers proposed $\beta$-sitosterolD-glucoside (Sit-G)-containing liposomes/DNA complex (Sit-G-liposome/DNA complex) for liver specific gene targeting. Transfection efficiency of the luciferase marker gene by Sit-G-liposome/DNA complex was found to be increased even in the presence of $10 \%$ serum in vitro, and was selectively high in the mouse liver reaching expression values up to an average of $14.9 \mathrm{pg}$ luciferase/mg tissue protein, compared with Tfx/DNA complex, which showed approximately three-fold higher gene expression than Sit-G-liposome/DNA complex in vitro (Figure 4) (Hwang 2001).

In order to accelerate endosomal exit of antisense acid drugs, Wang et al (2001) investigated the liposomal formulation with $\mathrm{pH}$-sensitive property to target hepatocytes. The $\mathrm{pH}$ sensitivity allows the liposome to escape from endosome/ lysosome at low $\mathrm{pH}$ value to release the entrapped AS-ODN in cytoplasm to take action. In their study, hepatocyte-targeting and $\mathrm{pH}$-sensitivity of liposome were analyzed by galactose-receptor competitive inhibition and hemolysis of chicken red blood cells. AS-ODNs, HCV363 against HCV 5 'NCR, was delivered via prepared liposome to transgenic HepG2 cells and evaluated for its inhibitory effect on lucif- erase expression controlled by HCV 5'NCR in HepG2 using luciferase assay system. The results showed that different concentrations of galactose solutions reduced the delivery effects of liposomes to some extent. In another study using pH-sensitive liposomes, Wen and coworkers (2004) proposed liposomes with four types of targeting molecules with galactose residue and $\mathrm{pH}$-sensitive lipids DC-chol/DOPE with integrated property of hepatocyte specificity and $\mathrm{pH}$ sensitivity. In their experiment, Liposome 18-gal showed desired hepatocyte specificity, $\mathrm{pH}$ sensitivity, low cytotoxicity, and high transfection efficiency.

Scherphof and coworkers (2002) studied the mechanism of interaction of liposomes with hepatocytes, in particular, the involvement of plasma proteins and lipoprotein receptors. Results showed remarkable differences in interactions and uptake mechanism among differently composed liposomes. They observed that Apolipoprotein E (ApoE) strongly enhances uptake of neutral liposomes, while uptake of charged liposomes was barely influenced by this protein, despite a higher binding capacity. ApoH (2-glycoprotein I), on the other hand, binds strongly to negatively charged liposomes (30\% PS), but appears to have little effect on in vitro uptake by various liver cells hepatocytes, kupffer cells or endothelial cells. A substantial fraction (in some cases $>50 \%$ ) of an injected dose of liposomes was taken up

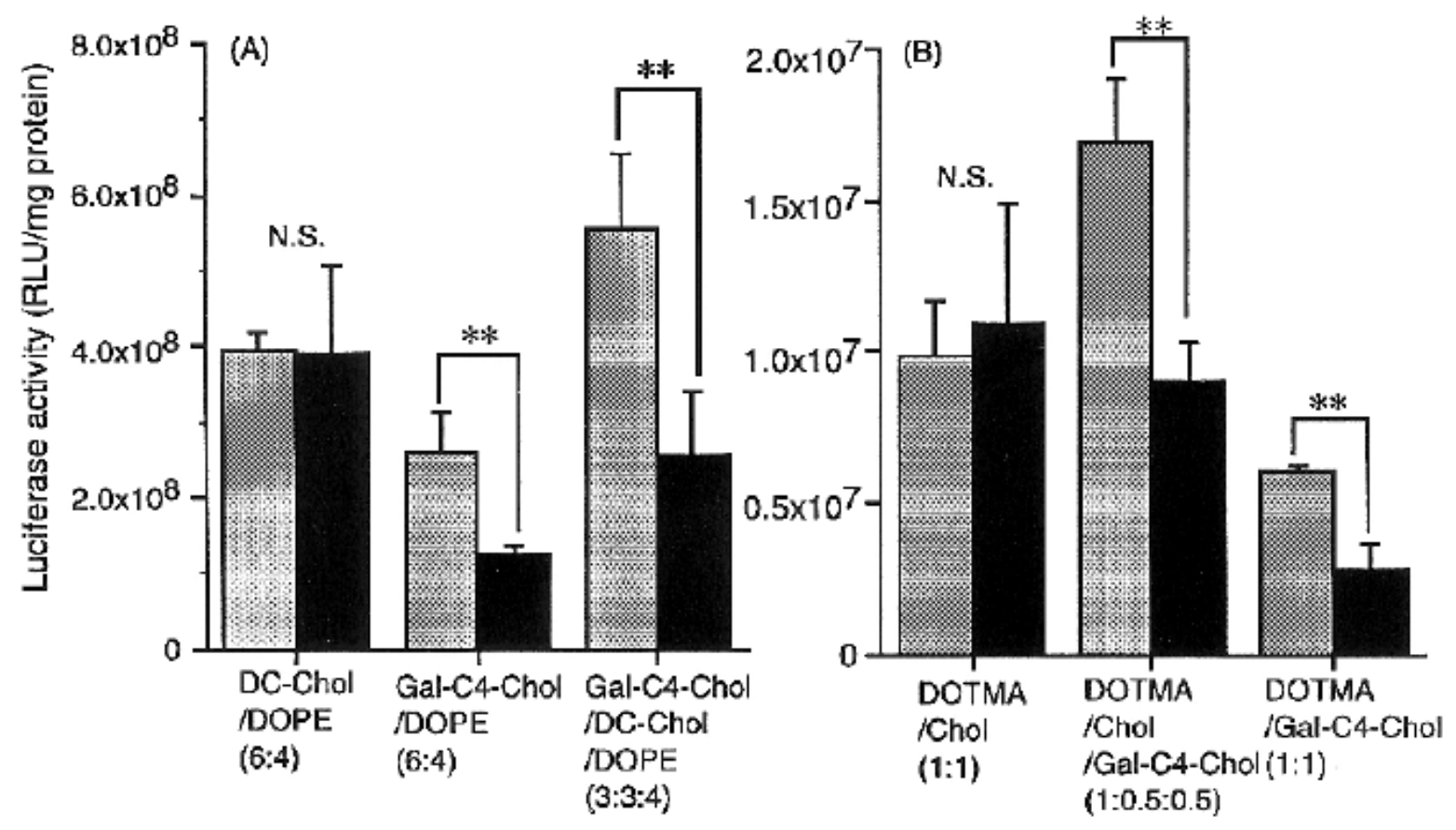

Figure 3 In vitro transfection activity of DNA/liposome complexes at a charge ratio of 2.3 in HepG2 cells. Cells were transfected with DNA/liposome complexes in the absence $(\dagger)$ and presence $(\dagger)$ of $20 \mathrm{mM}$ galactose. DOPE containing liposome/DNA complexes $(\mathbf{A})$ and DOPE noncontaining liposome/DNA complexes (B) were applied to the cells. DNA concentration was fixed at $0.5 \mu \mathrm{g} / \mathrm{ml}$ in all experiments. Statistical analysis was performed by analysis of variance (**indicated $\mathrm{p}<0.0 \mathrm{I} ; \mathrm{NS}$, not significant). Each value represents the mean 6 SD values $(n=3)$ (Adapted from Kawakami et al 2000). 


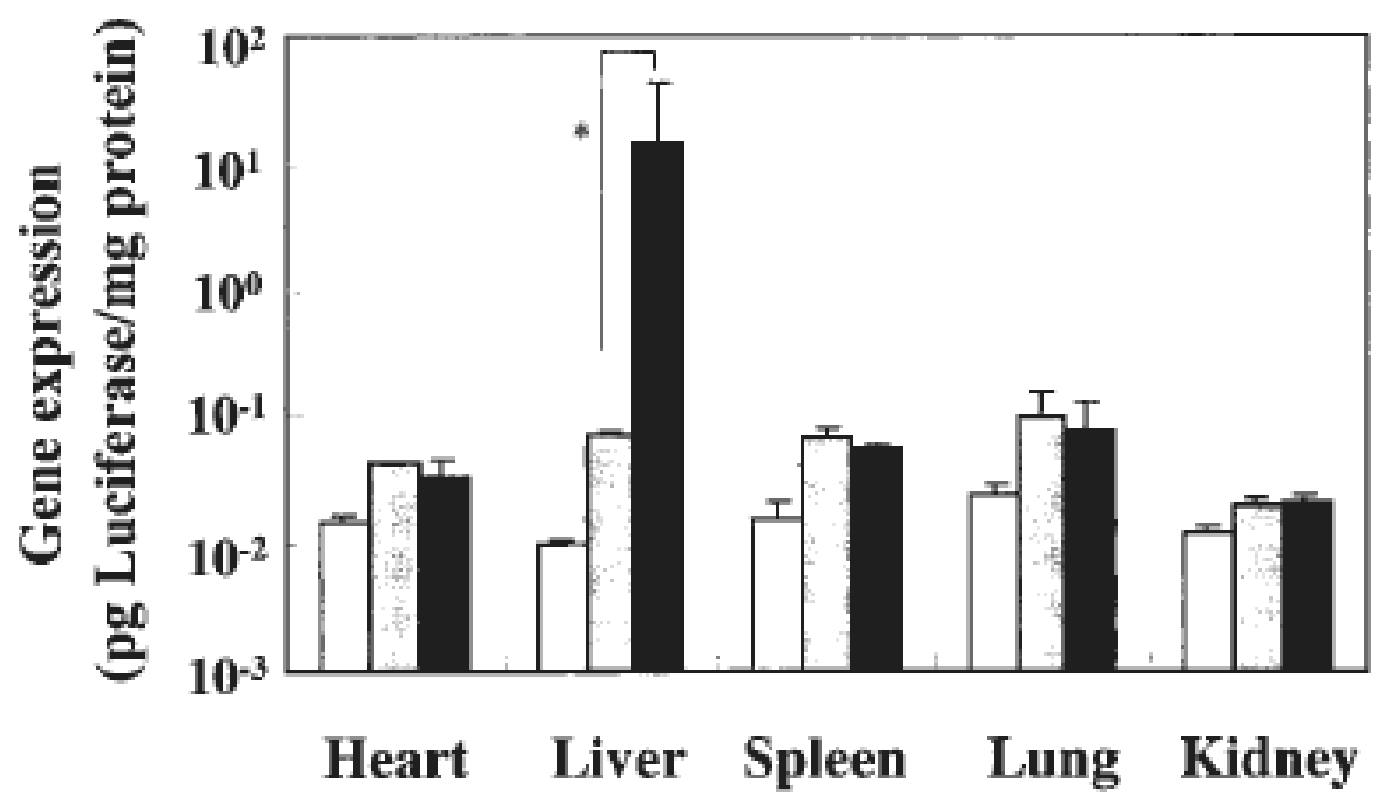

Figure 4 Biodistribution of gene expression $24 \mathrm{~h}$ after intravenous injection with plasmid DNA (50 $\mu \mathrm{g})$ complexed with liposomes or Tfx into mice (Adapted from Hwang et al 200I).

by the hepatocytes without the need for active targeting. In many cases, the attachment of (ga)lactosyl moieties on the liposomal surface causes an increase in uptake by the liver macrophages at the expense of the hepatocytes. Furthermore, Murao and coworkers (2002) investigated the effects of the lipid composition of galactosylated liposomes on their targeted delivery to hepatocytes. They prepared several types of liposomes using distearoyl-L-phosphatidylcholine (DSPC), cholesterol (Chol) and cholesten-5-yloxy-N-(4-((1-imino2-D-thiogalactosylethyl)amino) butyl)formamide Gal-C4Chol), and labeled with $\left[{ }^{3} \mathrm{H}\right]$ cholesterol hexadecyl ether. Their tissue disposition was investigated in mice following intravenous injection. The $\left[{ }^{3} \mathrm{H}\right] \mathrm{D}-\mathrm{SPC} / \mathrm{Chol} / \mathrm{Gal}-\mathrm{C} 4-\mathrm{Chol}$ (60:35:5) liposomes exhibited extensive hepatic uptake then $\left[{ }^{3} \mathrm{H}\right] \mathrm{DSPC} / \mathrm{Chol}$ (60:40) liposomes in HepG2 cells. Separation of the liver cells showed that galactosylated liposomes are preferentially taken up by hepatocytes, whereas those lacking Gal-C4-Chol distribute equally to hepatocytes and nonparenchymal cells (NPC). Increasing the molar ratio of DSPC to $90 \%$ resulted in enhanced NPC uptake of both liposomes, suggesting their uptake via a mechanism other than asialoglycoprotein receptors. DSPC/Chol/Gal-C4-Chol (60:35:5) and DSPC/Chol/Gal-C4-Chol (90:5:5) liposomes exhibited similar binding to the surface of HepG2 cells, but the former were taken up faster by the cells. In case of viral vectors, it has been known that intra-arterial administration is more efficient than intravenous, though cationic lipid vectors have not been compared in this way, Choi and co-workers
(2002) compared the efficiency of intra-arterial, intraportal, and intravenous route to deliver cationic lipid emulsion/DNA complex in rat liver. It was found that the cationic lipid emulsion/DNA complex efficiently transfected the various organs via the different routes of administration. Liver luciferase values were found significantly higher in the intra-arterial or intraportal administered groups.

In another report, a novel lipidic vector, composed of DOTAP/Chol liposomes, asialofeutin (AF), protamine sulfate and DNA, has been shown to improve significant levels of gene expression in HepG2 cells and in the liver upon i.v. administration. It was observed that, upon addition of free AF, the uptake by cells having ASGP-R on their plasma membrane was decreased, indicating that AF-lipoplexes were taken up specifically by cells via ASGP-R mediated endocytosis. Results obtained from transfections performed in ASGP-R negative cells, ie, HeLa cells, confirmed this mechanism. Further, on addition of the condensing peptide, protamine sulfate, smaller complexes were obtained, which further enhanced the uptake of AF-complexes in HepG2 cells and in the liver (Arangoa et al 2003).

Fumoto and coworkers (2004) proposed, enhanced hepatocyte-selective in vivo gene expression by stabilized galactosylated liposome/plasmid DNA complex using sodium chloride for complex formation. They demonstrated that the presence of an essential amount of sodium chloride $(\mathrm{NaCl})$ during the formation of cationic liposome/plasmid DNA complexes (lipoplexes) stabilizes the lipoplexes 
according to the surface charge regulation (SCR) theory. It was observed that upon intraportal administration, the galactosylated SCR lipoplexes ( 5 and $10 \mathrm{mM} \mathrm{NaCl}$ solution in lipoplex) resulted 10-20-fold higher hepatic transfection activity than that of galactosylated conventional lipoplexes in mice. The transfection activity in hepatocytes of galactosylated SCR lipoplexes was significantly higher than that of conventional lipoplexes, and pre-exposure to competitive asialoglycoprotein-receptor blocker significantly reduced the hepatic gene expression, suggested that hepatocytes were responsible for high hepatic transgene expression of the galactosylated SCR lipoplexes.

Bartsch and coworkers (2004) proposed stabilized lipid coated lipoplexes for the delivery of AS-ODNs to liver endothelial cells in vitro and in vivo. In their study, the behavior of untargeted coated cationic lipoplexes (CCLs) was compared with CCLs that were targeted to scavenger receptors on liver endothelial cells by covalent coupling of the poly-anion aconitylated human serum albumin (Aco-HSA) to the particle surface. Sun and coworkers (2005) studied galactosylated liposome-polycation-DNA complexes (LPD) as potential gene carriers to cells. In their study, four cholesterylated thiogalactosides with different spacer length were synthesized to formulate novel lipid-polycation-DNA (LPD) complexes, which were composed of galactosylated cationic liposomes, protamine sulfate and plasmid DNA. The galactosylated LPD complexes significantly improved the levels of gene expression in cultured hepatoma cells, HepG2 and SMMC-7721. Moreover, increased transfection activity was not observed in mouse fibroblasts L929 for galactosylated LPD. Cytotoxicity assay of galactosylated LPD complexes showed no toxicities to L929 cells and HepG2 cells.

Galactose density on liposomal surface also plays an important role in ASGP-R mediated uptake. Managit and coworkers (2005), prepared liposomes containing various molar ratios of cholesten-5-yloxy-N-(4-((1-imino-2-Dthiogalactosylethyl)formamide (Gal-C4-Chol) as a ligand for asialoglycoprotein receptors to study the effect of the galactose content of Gal-liposomes. They observed that after i.v. injection, Gal-liposomes having Gal-C4-Chol of $3.5 \%, 5.0 \%$, and $7.5 \%$, rapidly disappeared from the blood and exhibited rapid liver accumulation with up to $\sim 80 \%$ of the dose within $10 \mathrm{~min}$, whereas Gal-liposomes having low Gal-C4-Chol (1.0\% and 2.5\%) showed a slight improvement in liver accumulation compared with bare-liposomes. Gal liposomes with high Gal-C4-Chol were preferentially taken up by hepatocytes and the highest uptake ratio by parenchymal cells to nonparenchymal cells was observed with Gal-liposomes having of 5.0\% Gal-C4-Chol.

Recently, Wong and coworkers (2006) reported a versatile $\mathrm{T} 7$ phage tail fiber ( $\mathrm{p} 17)$ peptide to target proteins, polymers, siRNA and also particles such as DNA polyplexes and liposomes to hepatocytes. This peptide possesses 33 amino acid sequence within the 17 coiled-coil rod domain. The ability of this hepatocyte-targeting peptide to target DNA-containing particles suggests that it can be useful in the development of both nonviral and viral vectors. Delivery of ODNs to specific cells and maintenance of their biological functions are important for nucleic acid therapy. C-myc AS-ODNs are effective to suppress proliferation of human hepatocellular carcinoma and tumor growth of mice hepatoma model. Serum proteins impose severe barrier in gene delivery. Serum contains anionic compounds that quite often complex with positively charged transfection reagents, resulting in reduced transfection (Ghosh et al 2000). In order to transfer gene even in presence of high concentration of serum, Garcia and coworkers (2007) explored serum-resistant lipopolyplexes by employing PEI $(800,25$, and $22 \mathrm{kDa})$ and DOTAP and cholesterol, for gene delivery specifically to liver tumor cells. All vectors were found to be highly effective to protect DNA from DNAse I attack and transfer DNA efficiently to liver tumor cells. Among all developed systems, complexes formed with linear PEI $(22 \mathrm{kDa})$ were shown to be more effective and efficient than conventional lipopolyplexes and polyplexes. The similar trend was observed in the presence of the therapeutic gene pCMVIL-12, while keeping cell viability more than $80 \%$.

Bondi and coworkers (2007) proposed novel cationic solid-lipid nanoparticles (SLN) as nonviral vectors for gene delivery into liver cancer cells. Cationic SLN were able to form stable complexes with DNA and to protect it from DNase I digestion. In vitro studies shows that both SLN and SLN-DNA complexes exhibited a low degree of toxicity on human liver cancer cells. Further, SLN-DNA complexes were able to promote transfection of liver cancer cells.

Thus, the most significant biological consequence of modification of liposomes with galactose moiety is resulted in sharp increase in gene delivery efficiency in hepatocytes cells by virtue of ASGP-Rs. Gene transfer facilitated by these receptors is carried out by high affinity interaction between galactose ligand and respective receptors on the surface of liver parenchymal cells. Optimization of the co-lipid type of cationic liposomes, the charge ratio of the liposome - DNA complexes, ligand density and some physicochemical 
considerations will lead to further improvements in hepatic gene delivery using glycosylated liposomes.

\section{Polycation mediated liver specific gene targeting \\ Poly-L-lysine}

Poly-L-lysine (PLL) is a cationic, biocompatible and biodegradable polymer consists of only primary amines, which allow easy chemical modifications. Further, PLL can be substituted with targeting moiety to specifically target hepatoma cells. Lactoferrin (LF) is a globular multifunctional protein with antimicrobial activity and belongs to the transferrin family of nonheme iron binding glycoprotein. LF was used as a specific ligand for gene delivery to hepatocytes. In one such experiment, bovine lactoferrin and human lactoferrin were conjugated to PLL using 1-ethyl-3-(3dimethylaminopropyl) carbodiimide (EDC). Results showed that the $\mathrm{Lf} / \mathrm{pL}$ conjugates prepared by this method efficiently transferred the reporter genes, CAT and LacZ genes, to HeLa and hepatic cells. The bovine lactoferrin (bLf)/pL and human lactoferrin (hLf)/pL conjugates could transfer the reporter genes to various hepatocytes including primary mouse hepatocyte, Hepa 1-6, SK-Hep1 and Chang liver, but not to NIH 3T3 mouse fibroblast cells, indicating that the $\mathrm{Lf} / \mathrm{pL}$ conjugates conferred hepatocyte-specific gene transfer (Oh et al 1997).

Yang and coworkers (2000) compared the effects of liposomes and glyco-poly(L-lysine) (GLL) on liver targeted uptake and expression of plasmid in rat liver. In this study, they found that expression of plasmid mediated by both liposome and GLL decreased within a week. Both carriers efficiently delivered the plasmid, but GLL was found to be much better as compared to liposome concerning the distribution and plasmid expression in target organ liver. Hyaluronic acid (HA) is a nonsulfated glycosaminoglycan distributed widely throughout connective, epithelial, and neural tissues. It is one of the chief components of the extracellular matrix, contributes significantly to cell proliferation and migration, and may also be involved in the progression of some malignant tumors. Liver sinusoidal endothelial cells (SECs) possess unique receptors that recognize and internalize HA. Takei and coworkers (2004) proposed targeted gene delivery using hyauronate-grafted-PLL copolymer. In organ distribution of a ${ }^{32} \mathrm{P}$-radiolabeled plasmid (pSV $\beta$-galactosidase expression) complexed to PLL-g-HA, the complex was delivered to the liver. After 1 hour of injection, $>93 \%$ of the injected counts was detected in the liver, while DNA, complexed to PLL, was distributed mostly in the lungs. These observations suggest that on decorating the PLL with ligands such as lactoferrin and galactose, efficient gene carriers specific to hepatocytes can be engineered.

\section{Polyethyleneimine}

Among all polycations, polyethyleneimine (PEI) is found to be very efficient due to its inherent proton sponge property. Various Gal-PEI (MW 1800, 10000, 70000) derivatives were synthesized and investigated their potential as a targetable vector to ASGP-R-positive cells. Transfection efficiency was found highest with PEI (1800) in HepG2 cells (Morimoto et al 2003). In another experiment, Kunath and coworkers (2003), proposed galactosylated PEI with broad range of degree of substitution $(3.5 \%-31 \%)$ of all amino groups. Photon correlation spectroscopy observation showed that the size of Gal-PEI-DNA complexes was found to increase with increasing galactosylation. Cell toxicity was also found to diminish with increasing galactosylation. However, the transfection efficiency was slightly increased in HepG2 cells.

In order to target c-myc AS-ODNs on human hepatocellular carcinoma cell line Bel-7402, Jiang and Zhang (2004) developed Gal-PEI delivery vector with improved transfection efficiency. In their study, Gal-PEI-c-myc AS-ODN showed high targeting delivery effect on Bel-7402 cells, which enhances the intercellular concentration of c-myc AS-ODN effectively, but it had no such effects on U937 and Raji cells. The use of PEI as gene carrier is, however, limited due to cytotoxicity and nonspecific interactions with serum proteins. To overcome these bottlenecks, PEI was coupled with poly(vinyl pyrrolidone) (PVP) as hydrophilic group to reduce cytotoxicity and lactose bearing galactose group for hepatocyte targeting. The galactosylated-PEI-graft-PVP (GPP) complexes showed good DNA binding capacity and efficiently protect DNA from nuclease attack. The GPP also exhibited good transfection efficiency in HepG2 cells, and displayed low cytotoxicity. These results establish the potential of sugar anchored cationic polymers. The surface property of cytotoxic polymer like PLL and PEI can be modified using lactoferrin and galactose, to improve their transfection efficiency specifically to liver parenchymal cells.

\section{Chitosan}

Among the large number of cationic polymers known, chitosan is shown to be an effective vector that is able to condense and deliver DNA in vitro and in vivo. Chitosan is a naturally occurring linear polysaccharide consisting of $\beta$ - $(1,4)$ linked D-glucosamine and N-acetyl-D-glucosamine and produced by deacetylation of chitin (Felt et al 1998; Illum 
1998). It is a nontoxic, positively charged biodegradable and biocompatible polymer. Though, the use of chitosan as gene carrier is limited due to the low transfection efficiency and difficulty in transfecting into a variety of cell types, especially the hepatoma cells, researchers have tried to improve the transfection efficiency of chitosan to target hepatocytes. Park and coworkers (2000) described the coupling of lactobionic acid (bearing galactose unit) to chitosan for generating liver specificity and dextran was grafted on to galactosyalted chitosan (GC) for increasing its water solubility. As compared with the GC/DNA complexes, the stability of the galactosylated chitosan - graft-dextran (GCD/DNA) complexes was much higher and the GCD/DNA complexes transfected into Chang liver cells and that of Hep G2 cells possessing ASGP-R, indicative of specific interactions between ASGP-R on the cell surface and galactose ligands on chitosan. They also explored galactosylated chitosan (GC)-graft-poly(ethylene glycol) (PEG) (GCP) as a promising gene carrier and found that GCP/DNA complexes were effective in transfection experiments into Hep G2 cells and could provide protection to DNA from enzymatic degradation (Park et al 2001). However, the transfection efficiency of both the carriers was found to be lower than that of lipofection.

In an alternative strategy, poly(vinyl pyrrolidone) (PVP) (10 and $50 \mathrm{KDa}$ ), an amphipathic polymer with properties similar to PEG except having a better retention in blood, were conjugated with galactosylated chitosan. The binding strength of GC-graft-PVP (GCPVP) 10K/DNA complexes measured by ethidium bromide binding assay was found to be superior to that of the GCPVP 50K/DNA, probably attributed to its higher flexibility due to the smaller size, whereas the DNAse I protection of GCPVP 10K/DNA complex was inferior to that of the GCPVP 50K/DNA. This indicated that effective complex formation required both higher binding strength and minimal molecular weight of polycation enough to induce the condensation of DNA (Park et al 2003). Gao and coworkers (2003) coupled, lactobionic acid (LA) bearing galactose group with LMWC for liver-specificity. In their experiment, a series of galactosylated-LMWC (Gal-LMWC) samples covering a range of galactose group contents were prepared and used to transfer $\mathrm{pSV}$ - $\beta$-galactosidase reporter gene into HepG2, L-02, SMMC-7721, and human cervix adenocarcinoma (HeLa) cell lines in vitro. Gal-LMWC/DNA complex showed a very efficient cell selective transfection to hepatocyte. The transfection efficiency of Gal-LMWCs increased with the degree of the galactosylation. Cytotoxicity of Gal-LMWC was determined by 3-(4,5-dimethylthiazol-2yl)-2,5-diphenyltetrazolium bromide (MTT) assay and the results showed that the modified chitosan has relatively low cytotoxicity, giving the evidence that the modified chitosan vector has the potential to be used as a safe gene-delivery system. Similarly, LA bearing galactose group was coupled with water soluble chitosan (WSC) for hepatocyte specificity. The transfection efficiency into HepG2, which possesses ASGP-R, was higher than that recorded in case of $\mathrm{HeLa}$ without ASGP-R (Kim et al 2004).

Little is known on the use of chitosan for the delivery of AS-ODNs. Most of the cationic polymers being studied for gene delivery are too large and their surface charge density is too high to deliver AS-ODNs. Their complexation with AS-ODNs is a difficult problem because of the large difference between the sizes of the two macromolecules. Due to their high surface charge density, the complexes of cationic polymers with AS-ODNs are so stable that they are taken up by the cells without releasing the AS-ODNs, which are, therefore, unable to show the antisense activity. However, galactosylated low molecular weight chitosan (Gal-LMWC) with low surface charge density may be probably suitable for the specific delivery of AS-ODNs in vitro and in vivo. Gao and coworkers (2005) have demonstrated that Gal-LMWC can be used not only as the vector for plasmid DNA, but also as the vector for AS-ODNs in HepG2 cells. Results showed that Gal-LMWC could form stable nano-complexes with plasmid DNA or AS-ODNs by the electrostatic interactions. Transfection efficiency of Gal-LMWC/ASO complexes or Gal-LMWC/plasmid DNA complexes largely depends on the $\mathrm{N} / \mathrm{P}$ ratio (Figure 5). The results of inhibition experiments further confirmed that the enhanced transfection efficiency was due to the ASGR mediated endocytosis of the gal-LMWC/ ASO complexes or Gal- LMWC/plasmid DNA complexes. The resulting complexes were also found to possess low cytotoxicity (Figure 6).

Furthermore, in order to improve transfection efficiency of water soluble chitosan, lactobionic acid bearing galactose group was coupled for liver specificity and PEI was conjugated to galactosylated chitosan (GC) / DNA complexes to enhance the transfection efficiency via proton sponge effect (Kim et al 2005). Initially, the effect of PEI on the transfection efficiency of WSC/DNA complex was studied in HeLa, A549 and 293 T cells, and bafilomycin A1 was used to ascertain the mechanism of synergistic effect. The conjugation of PEI with WSC/DNA and GC/DNA complexes dramatically increased the luciferase expression by 10 - to 1000 -fold in various cell lines, and the synergistic effect was proved to be induced by proton sponge effect of PEI. The transfection of GC/DNA complexes in HepG2 was 
(a)

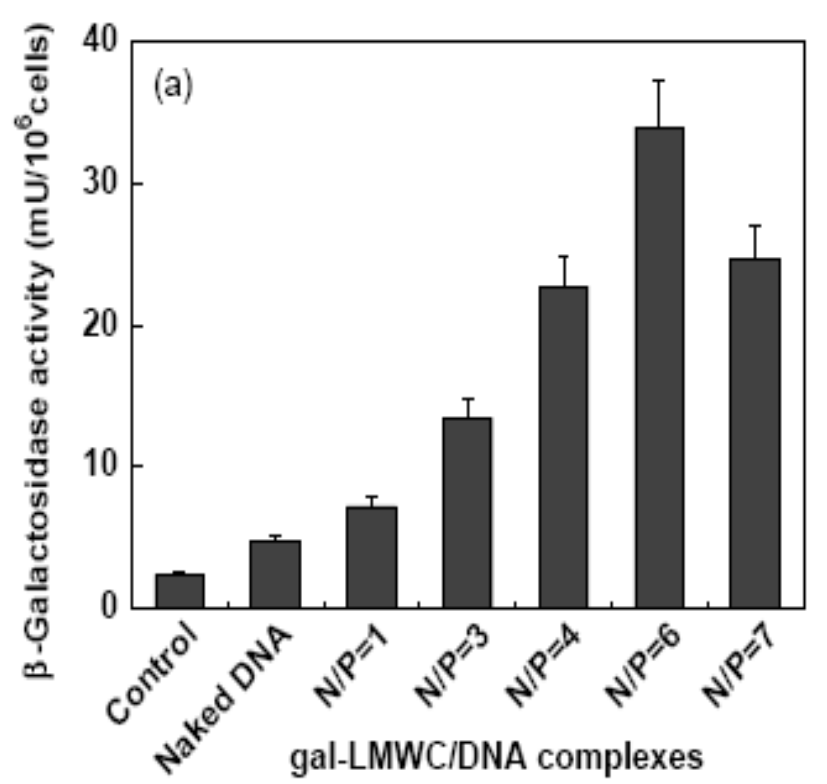

(b)

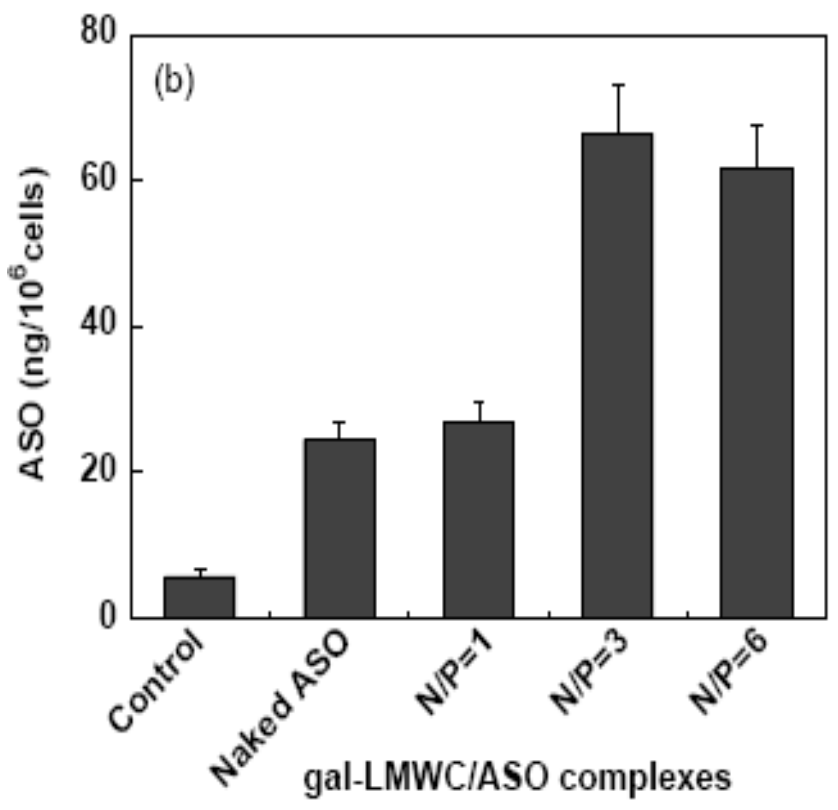

Figure 5 N/P ratio dependent transfection efficiency of gal-LMWC/plasmid DNA complexes (a) and gal-LMWC/ASO complexes (b) in HepG2 cell line (Adapted from Gao et al 2005).

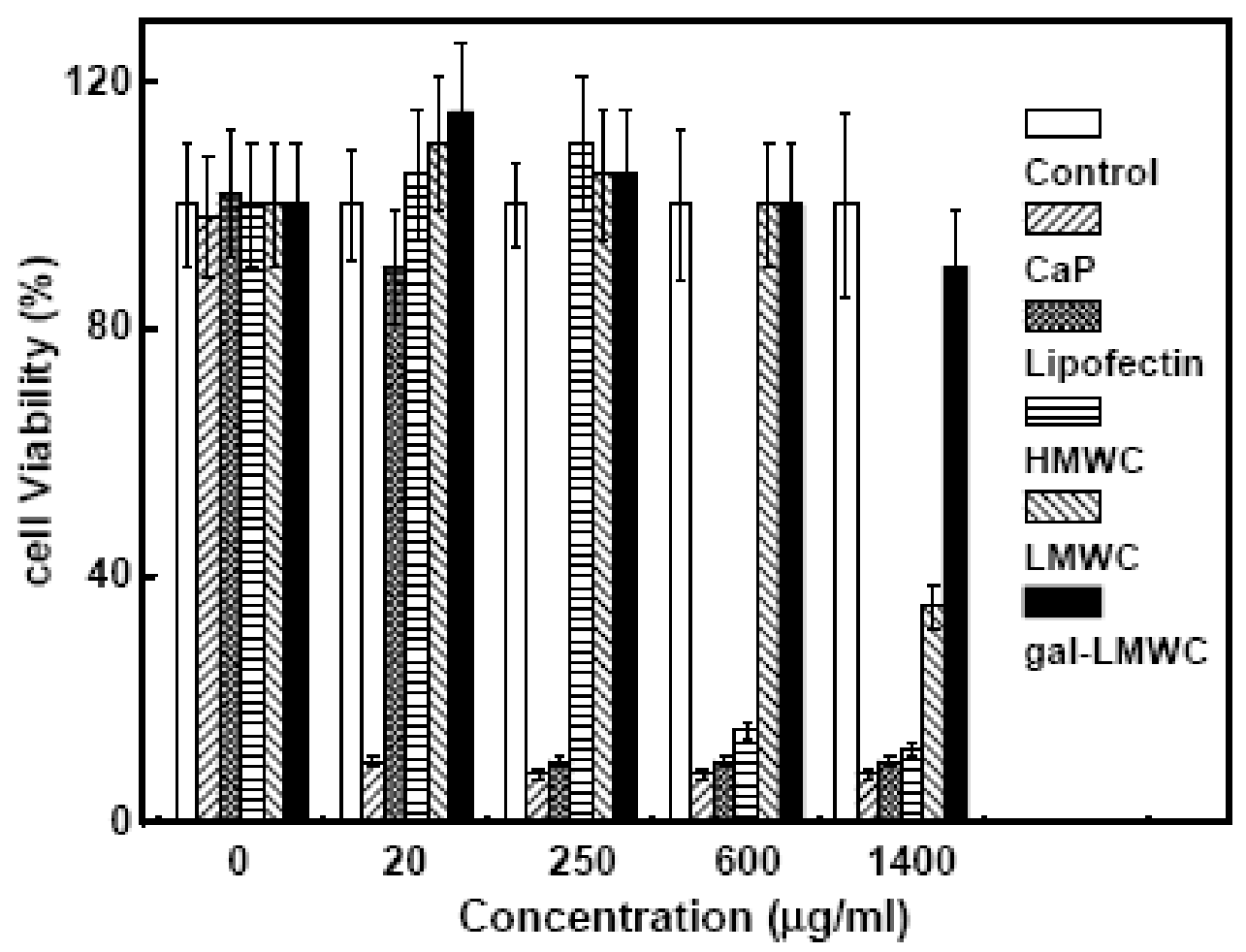

Figure 6 MTT assay for cytotoxicity of CaP, Lipofectin, HMWC, LMWC, and gal-LMWC in HepG2 cell line (Adapted from Gao et al 2005). 
much higher than that of WSC/DNA even after conjugation with PEI, and was significantly inhibited in the presence of galactose. However, transfection efficiency decreased in the presence of bafilomycin A1, a specific inhibitor of vacuolar type $\mathrm{H}^{+}$by inhibiting endo-/lysosomal proton pump (Figure 7). Cytotoxicity of PEI was also significantly reduced by conjugation with GC/DNA complex. Very recently, Satoh and coworkers (2007) proposed in vitro gene delivery to HepG2 cells using galactosylated 6-amino-6-deoxychitosan as a DNA carrier. In their study a series of galactose-modified 6-amino-6-deoxy chitosan (Gal-6ACT) with degrees of substitution ranging from $3 \%$ to $50 \%$ per pyranose were prepared by reductive alkylation with lactose. A significant increase in transfection efficiency was observed at degree of substitutions ranging from $18 \%-50 \%$ and at $\mathrm{N} / \mathrm{P}$ values ranging from 1.5-2.5, and Gal-6ACT was found to be $\sim 10$ times more efficient than 6ACT. Interestingly, Gal-6ACT with a degree of substation of $38 \%$ also efficiently transfect both A549 and HeLa cells lacking the galactose receptor. These results suggest that the enhancement of transfection efficiency of Gal-6ACT was not due to the increase of receptor-mediated cellular uptake. Thus the sugar modification significantly improves the transfection efficiency of chitosan.
Other polycation based nanocarriers have also been investigated for hepatocytes specific gene delivery (Table 1).

\section{Phosphorous-containing polymer}

Phosphorus-containing polymeric gene carriers have also been reported to enhance transfection efficiency. In one of such reports, a series of cationic polymers, polyphosphoramidates (PPAs), with an identical backbone, same side chain spacer, similar molecular weights but different charge groups containing primary to quaternary amino groups have been synthesized (Wang et al 2004). These PPAs did not show significant capacity to buffer endosomes within $\mathrm{pH} 5-7$, even though transfection mediated by PPA-EA seemed to be limited by endolysomal escape. Results showed that endocytosis of DNA mediated by PPAs was also similar (17\%-22\%) for all four PPAs. However, the transfection efficiency of these PPAs varied significantly. In vitro transfection efficiency of PPAs decreased in the order of PPA-EA $>$ PPA-MEA $>$ PPA-DMA PPA-TMA. As shown in Scheme 1, Zhang and coworkers (2005) prepared galactosylated polyphosphoramidates nanoparticles (Gal-PPAs) with varied degrees of ligand substitution $(6.5 \%, 12.5 \%$, and $21.8 \%$ ) with an aim to transfer DNA in liver cells. It

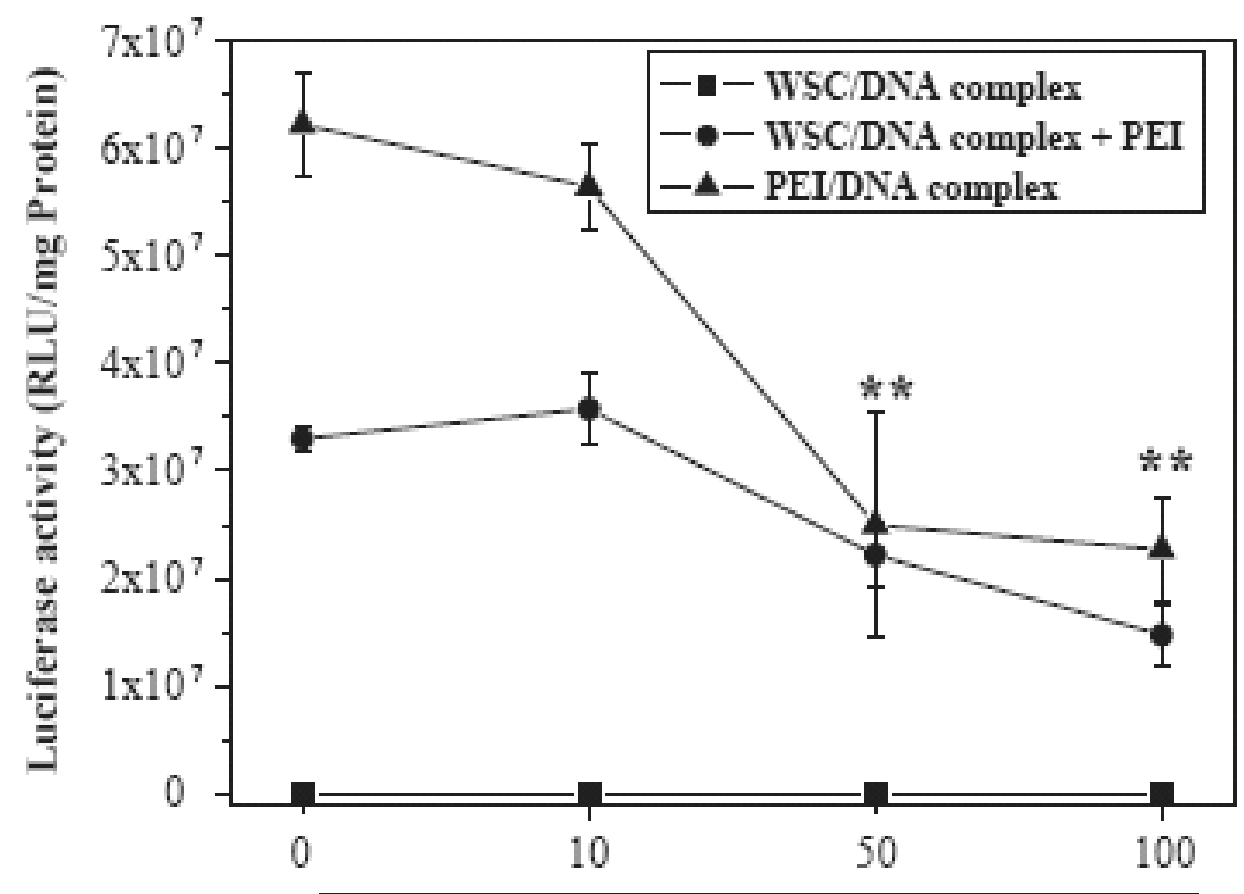

Concentration of bafilomycin $\mathrm{A}(\mathrm{nM})$

Figure 7 Effect of bafilomycin A I on the gene transfection in 293 T cells.WSC/DNA complex was prepared at charge ratio I0 and the amount of PEI used was $0.5 \mathrm{Ag}$. Different amounts of bafilomycin AI diluted in DMSO were put into the wells. After 10 min incubation period, transfection solutions were added into the wells. The cells were incubated in the transfection solution for $4 \mathrm{~h}$ and then in the growth medium for $48 \mathrm{~h}$ (Adapted from Kim et al 2005). 
Table I Studies performed with various nanocarriers for hepatocytes specific gene delivery

\section{Engineered constructs \\ Gal-PEG-grafted PLL}

polymeric gene carrier

Lactosylated PLL

Asialofetuin-PLL conjugate [(Gal-6)3Lys2-bA] for hepatocytes targeting Nonenzymatic glycosylation of poly-l-lysine

DNA/lactosylated polylysine complexes

Lactose-PEG-grafted PLL

PLL/DNA polyplexes

Lactose-PEG grafted PLL

Galactosylated PEI/DNA complexes

Glycosylated-PEI

Poly(2-(dimethylamino)ethyl methacrylate - N-vinyl2-pyrrolidone (DMAEMANVP)-b-PEG-galactose as gene delivery vector for hepatocytes

Pullulan derivatives with chelate residues based on metal coordination

\section{Purpose/result}

- Form stable and soluble complexes with nucleic acids (which in turn are able to efficiently transform cells)

- PEG attached to the PLL gives better solubility to the carrier complex and improved transfection efficiency without considerable cytotoxicity.

- The transfection efficiency of HepG2 cells with pSV2Luc/lactosylated PLL complexes was greatly enhanced in the presence of chloroquine/fusogenic peptide.

- In the presence of the fusogenic peptide, the luciferase activity in HepG2 cells was 10 fold larger than that of cells transfected with PSV2Luc/lactosylated PLL complexes in the presence of chloroquine.

- Asialofetuin-PLL conjugate efficiently internalize ODN in hepatoma cell line PLC/PRF/5.

- Trigalactosylated bisacridine [(Gal-6)3Lys2-bA] compound could mediate the binding of DNA to both the ricin lectin and to primary hepatocytes.

- PLL was crosslinked to an asialoglycoprotein, and the resulting conjugate was complexed with the DNA.

- The electrostatic binding between DNA and PLL asialoglycoprotein ensures efficient i.v. delivery complex to the liver by receptor mediated endocytosis.

- At high concentrations of chloroquine induced the dissociation of plasmid DNA/lactosylated PLL complexes and enhanced the transfection.

- The luciferase activity was enhanced in the presence of primaquine, a chloroquine analogue, but was not increased when transfection was performed in the presence of ammonium chloride, methylamine, spermine, or monensin, compounds known to neutralize the $\mathrm{pH}$ of the endocytotic vesicle lumen as chloroquine does.

- Transfection experiments showed that Lac-PEG-PLL efficiently delivers DNA to a hepatoma cell line in vitro (at a 1:3 weight ratio of DNA to carrier).

- As the lactose-PEG substitution content increased up to $30 \%$, the transfection efficiency increased, which demonstrated that the lactose serves as a targeting moiety. No considerable cytotoxicity was observed due to Lac-PEG-PLL. The use of chloroquine increased transfection efficiency that indicated the involvement of hydrolytic degradation of the system in lysosome.

- Attachment of asialoorosomucoid to PLL increased the PLL chain length required for efficient DNA binding in saline and for efficient DNA condensation.

- Attachment of asialoorosomucoidllessened, but did not eliminate, the aggregation of PLL polyplexes, and did not result in efficient delivery of polyplexes to hepatocytes.

- Conjugation of PEG to PLL sterically stabilized resulting polyplexes at neutral charge ratios by shielding the surfaces.

- Lac-PEG-PLL was shown to protect DNA against nuclease action in a DNase I protection assay.

- Lac-PEG-PLI, formed complexes with plasmid DNA gave little cytotoxicity, and showed increased efficiency of gene transfer into hepatoma cells in vitro.

- Lac-PEG-PLL was more efficient than Lipofectin or galactose-PEG-PLL in transfection efficiency.

- $5 \%$ of the PEI nitrogens were grafted with a linear tetragalactose structure (IGal4), small and stable particles were formed upon complexation with plasmid DNA.

- Slightly charged PEI-IGal4/DNA complexes were very selectively galactosylated-PEI vector to transfect hepatocytes.

- Gal-PEl was prepared using titanium (IV) isopropoxide and sodium borohydride, as a substitute for the highly toxic sodium cyanoborohydride method.

- Systems were found to be nontoxic and efficient transfection agent in HepG2 cells.

- Poly(DMAEMA-NVP)-b-PEG-galactose in combination with an endosomolytic peptide, KALA demonstrated sufficient transfection efficiency as high as that of commercial agent.

- i.v. injection of the pullulan derivatives-plasmid DNA conjugates with $\mathrm{Zn}^{2+}$ coordination significantly enhanced the level of gene expression in the liver.

- A fluorescent-microscopic study revealed that the plasmid DNA was localized at the liver after injection of the pullulan-DTPA-plasmid DNA conjugate with $\mathrm{Zn}^{2+}$ coordination.
Reference

United States Patent 6177274

Midoux et al (1993)

Reinis et al (1993)

Haensler and szoka

(1993)

Martinez-Fong et al

(1994)

Erbacher et al (1996)

Choi et al (1998)

Kwoh et al (1999)

Choi et al (1999)

Bettinger el al (1999)

Leclercq et al (2000)

Lim et al (2000)

Hosseinkhni et al

(Continued) 
Table I (Continued)

\begin{tabular}{|c|c|c|}
\hline Engineered constructs & Purpose/result & Reference \\
\hline Galactose-PEI-DNA & $\begin{array}{l}\text { - MTT and LDH assay confirmed that cytotoxicity of gal-PEI was found to decrease with } \\
\text { increasing galactosylation. } \\
\text { - Require necessity of careful optimization of polyplex composition for active gene targeting. }\end{array}$ & Kunath et al (2003) \\
\hline $\begin{array}{l}\text { Lactose-appended schizo- } \\
\text { phyllan }\end{array}$ & $\begin{array}{l}\text { - Schizophyllan (beta-I,3-glucan) derivative carrying lactose-appendages prepared by reduc- } \\
\text { tive amination, effectively mediates gene transfection into hepatocytes. }\end{array}$ & $\begin{array}{l}\text { Hasegawa et al } \\
(2004)\end{array}$ \\
\hline $\begin{array}{l}\text { Surface modified albumin } \\
\text { nanoparticles }\end{array}$ & $\begin{array}{l}\text { - In this study, Calcein loaded bovine serum albumin nanoparticle (Cal-BSA-NP) and bovine } \\
\text { serum albumin nanoparticles with their surface modified by glycyrrhizin (Cal-BSA-NP-GL) } \\
\text { were developed as a novel hepatocyte targeting based on active targeting technology medi- } \\
\text { ated by specific binding site of GL on rat cellular membrane. } \\
\text { - The uptake amount of Cal-BSA-NP-GL by rat hepatocytes was } 4.43-\text { fold higher than that of } \\
\text { Cal-BSA-NP and results shows significant difference in the uptake of Cal-BSA-NP-GL and } \\
\text { Cal-BSA-NP by hepatocytes. }\end{array}$ & Mao et al (2005) \\
\hline $\begin{array}{l}\beta \text {-(I-3)-D-glucan schizophyl- } \\
\text { lan for AS-ODN delivery }\end{array}$ & $\begin{array}{l}\text { - Galactose moieties were conjugated to the side chain of SPG to enhance cellular ingestion } \\
\text { through endocytosis mediated by ASGP-Rs. }\end{array}$ & Karinaga et al (2006) \\
\hline Chitosan-DNA nanoparticles & $\begin{array}{l}\text { - Chitosan-DNA nanoparticles showed several times higher luciferase expression in the liver } \\
\text { after retrograde intrabiliary infusion (RII). } \\
\text { - Luciferase expression by RIl of PEI-DNA nanoparticles was I7-fold lower than that of } \\
\text { chitosan-DNA nanoparticles. } \\
\text { - RIl of chitosan-DNA nanoparticles did not yield significant toxicity. }\end{array}$ & Dai et al (2006) \\
\hline $\begin{array}{l}\text { Surface modified magnetite } \\
\text { nanoparticles }\end{array}$ & $\begin{array}{l}\text { - In this report, superparamagnetic magnetite nanoparticles were surface-modified with } \\
\text { lactobionic acid (LA) to improve their intracellular uptake and ability to target hepatocytes. } \\
\text { - Cell culture experiment showed that LA-modified nanoparticles were internalized into } \\
\text { hepatocytes and atomic absorption spectrometer (AAS) measurement indicated that the } \\
\text { uptake amount of LA-modified magnetite into hepatocytes was higher than that of unmodi- } \\
\text { fied and control MA-modified nanoparticles. } \\
\text { - LA-modified nanoparticle solution was injected in rabbit and the magnetic resonance (MR) } \\
\text { images obtained showed that LA-coated nanoparticles were selectively accumulated onto } \\
\text { the hepatocytes }\end{array}$ & $\begin{array}{l}\text { Kamruzzaman et al } \\
(2007)\end{array}$ \\
\hline $\begin{array}{l}\text { Synthetic PEGylated gly- } \\
\text { coproteins for hepatocyte } \\
\text { targeting }\end{array}$ & $\begin{array}{l}\text { - PEGylated glycoproteins (PGPs) were synthesized by copolymerizing a Cys-terminated } \\
\text { PEG-peptide, glycopeptide, and melittin peptide by varying the ratio of PEG-peptide } \\
\text { (20\%-90\%) and melittin ( } 0 \%-70 \%) \text { with a constant amount of glycopeptide (10\%). } \\
\text { - Results shows that the level of gene expression mediated by PGP-DNA was } 5000 \text {-fold less } \\
\text { than direct hydrodynamic dosing of an equivalent amount of DNA and was independent of } \\
\text { the mol percent of melittin incorporated into the polymer, but dependent on the presence } \\
\text { of galactose on PGP. }\end{array}$ & Chen et al (2007) \\
\hline
\end{tabular}

was found that as galactose substitution increases, in vitro cytotoxicity of Gal-PPA decreases. Furthermore, binary and ternary nanoparticles of galactosylated PPA/DNA were prepared and used in transfection studies (Scheme 2). The results of this study revealed that in HepG2 cells and primary rat hepatocytes, the transfection efficiency mediated by ternary nanoparticles prepared with 6.5\% Gal-PPA was 6-7200 times higher than PPA-dipropylenetriamine (DPA)/DNA nanoparticles.

Recently, in a slightly different approach, Horiuchi and coworkers (2006) investigated and compared the transfection properties of nonglycosilated, singly and triply lactosefunctionalized derivatives of calix[4]resorcarene-based amphiphilic octaamine. They all bind to luciferase-encoding pDNA and transfection of HeLa and HepG2 cell lines showed decreasing expression efficiency and cytotoxicity with increasing number of lactose moieties. However, cell selectivity for HepG2 over HeLa increased with increasing the number of lactose residues. Concisely, the lactose moieties introduced were found to be charge-masking, aggregation-promoting, and toxicity-lowering.

\section{Lysosome disruptive elements to target hepatocyte}

It is well known that the transfection ability of nonviral gene delivery vectors is generally hampered by lysosomal degradation of the internalized DNA. Current vectors that enable the endo-lysosomal escape of macromolecules (ie, DNA, siRNA) are limited by their toxicity and by their ability to carry only limited classes of therapeutic agents. In an attempt to facilitate the escape of DNA from lysosomal compartment and enhancing the transfection efficiency in a cell-specific fashion, Van Rossenberg and coworkers (2002) developed a nontoxic cell specific lysosome disruptive 



Scheme I Synthetic scheme for PPA-DPA and galactosylated PPA-DPA (adapted from Zhang and coworker 2005).

element for hepatocyte specific gene transfer. In their experiment, two fusogenic peptides (INF7 and JTS-1) were tested for their capacity to disrupt lysosomes. INF7, a 23-mer peptide is derived from hemagglutinin (HA), and JTS-1, an artificial INF7 mimic designed for $\mathrm{pH}$-sensitive helix formation, were studied. INF7 was selected for coupling to a high affinity ligand for the ASGP-R, and $\mathrm{K}(\mathrm{GalNAc})_{2}$ to improve its uptake by liver parenchymal cells. Results showed that the parent peptide disrupted both cholesterol-rich and poor liposomes, while INF7-K(GalNAc), only induced leakage of cholesterol-poor liposomes only, making it eminently suitable for targeted fusogenic activity in parenchymal cells. The endosomal membrane of eukaryotic cells is known to contain $<5 \%$ cholesterol, this implies that the conjugate displays a higher selectivity toward endosomal membranes. Although both INF7 and INF7-K(GalNAc) $)_{2}$ were found to increase the transfection efficiency of polyplex-mediated gene transfer to parenchymal liver cells by 30 -fold, only INF7-K(GalNAc) appeared to do so in an ASGP-R specific manner. In vivo, INF7-K(GalNAc) ${ }_{2}$ was specifically targeted to the mice liver, whereas INF7 was distributed evenly over various organs. In another study, Panyam and coworkers (2002) reported rapid (<10 min) endo-lysosomal escape of biodegradable nanoparticles (NPs) formulated from the copolymers of poly(DL-lactide-co-glycolide) (PLGA) and proposed that the mechanism of rapid escape is by selective reversal of the surface charge of NPs (from anionic to cationic) in the acidic endo-lysosomal compartment, which causes the NPs to interact with the endo-lysosomal membrane and escape into the cytosol.

\section{Bio-nanocapsules for hepatocyte specific gene transfer}

Recently, bio-nanocapsules (BNCs) have been demonstrated as efficient delivery vectors specifically targeting human hepatocytes (Nagaoka et al 2007). BNCs are composed of the recombinant envelope L-protein of hepatitis B virus. Previously, envelop proteins have been developed as vaccine for hepatitis B. The envelope of HBV is composed mainly of three closely related surface proteins that are known as the large (L), the middle (M) and the small (S) proteins. They are encoded in one open reading frame of HBV genome 


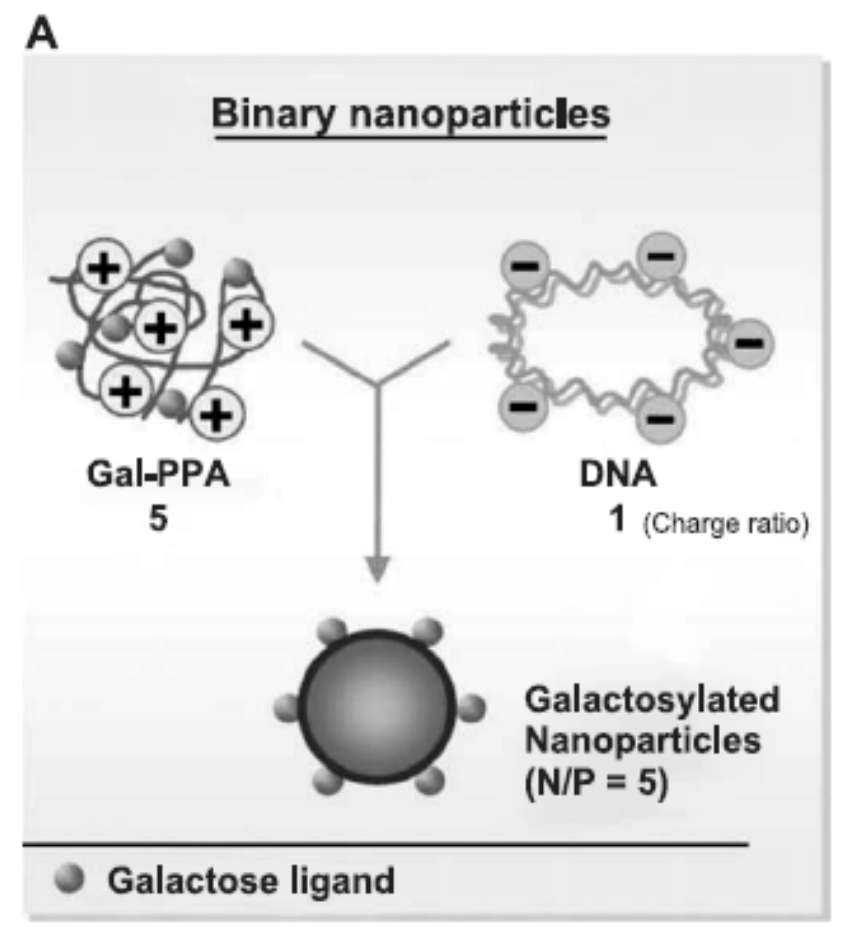

B

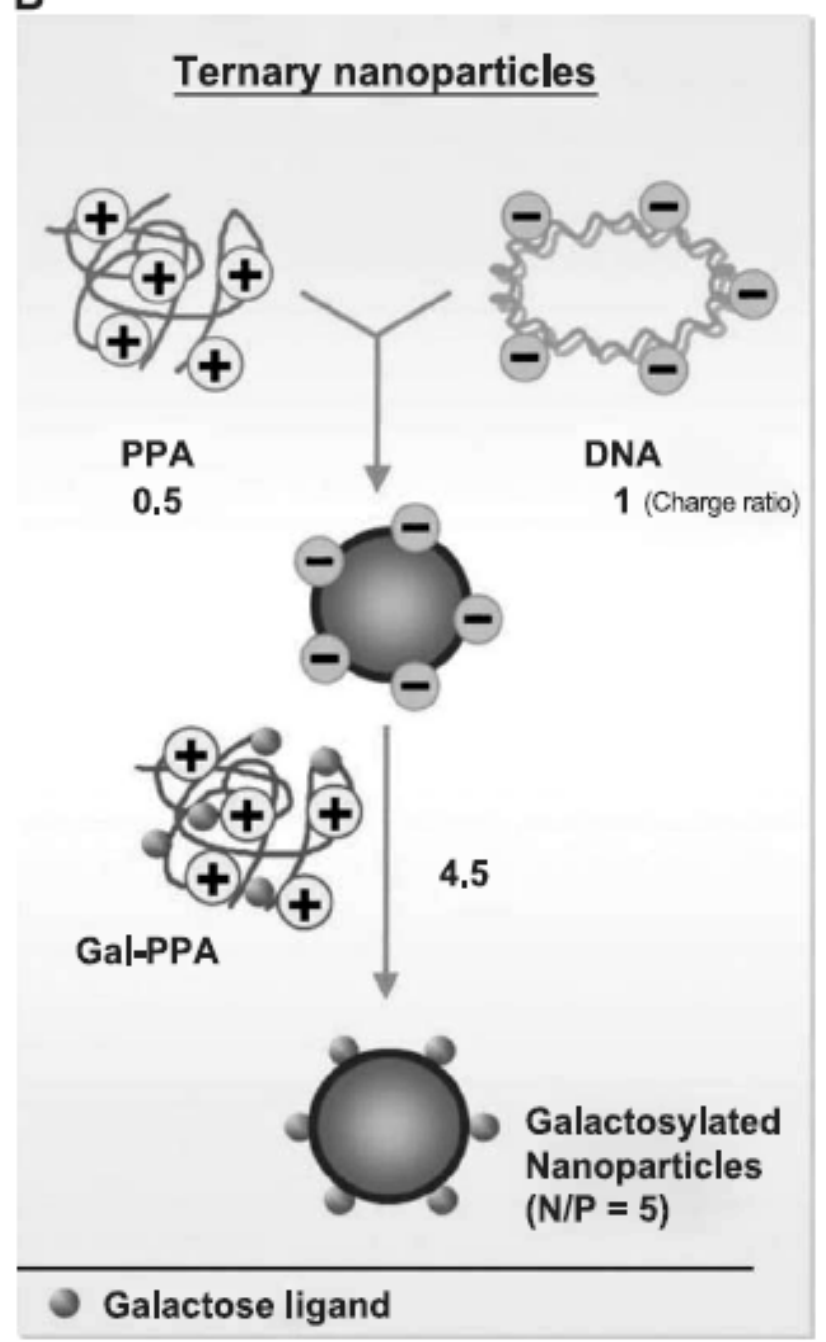

Scheme 2 Preparation of binary and ternary nanoparticles containing galactosylated PPA-DPA (adapted from Zhang and coworker2005).

translated from three different in-frame initiation sites. When these proteins were expressed, each S-, M- and L-protein was found to form hollow virus-like nanoparticles. The particle composed of L-protein showed, in particular, a specific affinity to human hepatocytes due to the hepatocyte recognition site localized in the amino terminus. For the purpose of developing safe and efficient delivery systems, vectors having a targeting potential for specific cells or tissues, Nagaoka and coworkers (2007) exploited the nanoparticles composed of recombinant envelope protein as bio-nanocapsule (BNC) prepared from mammalian cells or yeast cells. However, aggregation of envelope proteins in the BNCs may occur during long-term storage, which might be attributed to the false disulfide bridges and which could be overcome by the cysteine residues in the L-protein.

\section{Stability of nano-vectors}

The stability of nanoparticulate systems poses a serious challenge in gene/drug delivery research. Nanoparticle dispersion is a typical thermodynamically unstable system due to its large specific interfacial area. During storage, particle aggregation often occurs. Some efforts have been made towards increasing the physical stability of such a system. Lyophilization is one such technique used for this purpose. However, lyophilization has some disadvantages (particle size increases during the process of freeze drying and lyophilized nanoparticles may still aggregate after some time on storage).

The incorporation of various site directing molecules on nano-vectors confers them suitable stability in bio-fluids as well as site-specificity towards receptors. However, in some cases, ligands provide only stability and better structure 
integrity against harsh bio-environments encountered after oral/parenteral drug administration. Sunamoto and Iwamaoto (1986), and Sihorkar and Vyas (2001) reviewed stability issues of liposomal carrier systems. Unfortunately, majority of the experiments described were performed in vitro only and lack in in vivo data to correlate and interpretate the results.

\section{Conclusions}

Hepatocytes (the principal parenchymal cells of the liver) are a much sought-after target of gene therapy, because they play many unique roles in the physiology of the mammalian host. The liver poses formidable obstacles to hepatocyte-specific gene delivery. Many pharmaceutical nanocarriers that effectively deliver genes to other cell types do not efficiently target the hepatocyte. Advances in nanotechnology and cell biology provided new opportunities for drug/gene delivery research to focus hepatocyte by receptor mediated endocytosis. Several glycosylated nanocarriers have been developed and paved the way for biologically safe, site-specific and stable transgene expression. In past few years, receptor mediated cellular bioevents have received major attention in modern drug/gene delivery therapeutics, albeit the approach is just at nascent stage, it shows a promise in near future to develop DNA based pharmaceuticals for the effective managements of liver associated disorders.

\section{Abbreviations}

AS-ODNs, antisense oligonucleotide; siRNA, short interfering RNA; GIT, gastro intestinal tract; PEI, polyethyleimine; PAA, polyallylamine; PLL, poly-L-lysine; DOTMA, $\mathrm{N}$-[1-(2,3-dioleyloxy)propyl]-N,N,N-trimethylammonium chloride; DOPE, L-dioleoylphosphatidylethanolamine; Chol, cholesterol; PEG, polyethylene glycol; PLGA, poly(DL-lactide-co-glycolide); Gal-C4-Chol, Cholesten-5-yloxy-N-(4((1-imino-2-b-D thiogalactosylethyl)amino)butyl)formamide; CAT gene, chloramphenicol acetyltransferase gene; MTT, 3-(4,5-dimethylthiazd-2-yl)-2,5-diphenyltentrazolium bromide; DPA, dipropylenetriamine; PEG-DSPE, monomethox ypoly(ethyleneglycol)-distearoylphosphatidylethanolamine; DMAEMA, poly(2-(dimethylamino)ethyl methacrylate; NVP, N-vinyl-2-pyrrolidone.

\section{References}

Akhtar S, Hughes M, Khan A, et al. 2000. The delivery of antisense therapeutics. Adv Drug Deliv Rev, 44:3-21.

Arangoa MA, Duzgunes N, Tros de Ilarduya C. 2003. Increased receptormediated gene delivery to the liver by protamine-enhanced-asialofetuinlipoplexes. Gene Ther, 10:5-14.
Azzam T, Domb AJ. 2004. Current developments in gene transfection agents. Curr Drug Deliv, 1:165-93.

Bartsch M, Weeke-Klimp AH, Hoenselaar EP, et al. 2004. Stabilized lipid coated lipoplexes for the delivery of antisense oligonucleotides to liver endothelial cells in vitro and in vivo. J Drug Target, 12:613-21.

Bettinger T, Remy JS, Erbacher P. 1999. Size reduction of galactosylated PEI/DNA complexes improves lectin-mediated gene transfer into hepatocytes. Bioconjug Chem, 10:558-61.

Bondi ML, Azzolina A, Craparo EF, et al. 2007. Novel cationic solid-lipid nanoparticles as non-viral vectors for gene delivery. J Drug Target, 15:295-301.

Chen CP, Kim JS, Liu D, et al. 2007. Synthetic PEGylated glycoproteins and their utility in gene delivery. Bioconjug Chem, 18:371-8.

Choi YH, Liu F, Park JS, et al. 1998. Lactose-poly(ethylene glycol)-grafted poly-L-lysine as hepatoma cell-targeted gene carrier. Bioconjug Chem, 9:708-18.

Choi YH, Liu F, Choi JS, et al. 1999. Characterization of a targeted gene carrier, lactose-polyethylene glycol-grafted poly-L-lysine and its complex with plasmid DNA. Hum Gene Ther, 10:2657-65.

Choi BY, Chung JW, Park JH, et al. 2002. Gene delivery to the rat liver using cationic lipid emulsion/DNA complex: comparison between intra-arterial, intraportal and intravenous administration. Korean $J$ Radiol, 3:194-8.

Conner SD, Schmid SL. 2003. Regulated portals of entry into the cells. Nature. 422:37-43.

Cook SE, Park IN, Kim EM, et al. 2005. Galactosylated polyethyleniminegraft-poly(vinyl pyrrolidone) as a hepatocyte-targeting gene carrier. $J$ Control Rel, 105:151-63.

Crystal RG. 1995. Transfer of genes to human: early lessons and obstacles to success. Science, 270:404-10.

Dai H, Jiang X, Tan GC, et al. 2006. Chitosan-DNA nanoparticles delivered by intrabiliary infusion enhance liver-targeted gene delivery. Int J Nanomed, 1:507-522.

Elouahabi A, Ruysschaert JM. 2005. Formation and intracellular trafficking of lipoplexes and polyplexes. Mol Ther, 11:336-47.

Erbacher P, Roche AC, Monsigny M, et al. 1996. Putative role of chloroquine in gene transfer into a human hepatoma cell line by DNA/lactosylated polylysine complexes. Exp Cell Res, 225:186-94.

Felgner PL, Barenholz Y, Behr J-P, et al. 1997. Nomenclature for synthetic gene delivery systems. Hum Gene Ther, 20:511-12.

Felt O, Buri P, Gurny R. 1998. Chitosan: a unique polysaccharide for drug delivery. Drug DevInd Pharm, 24:979-93.

Fuhrer C, Geffen I, Huggel K, et al. 1994. The two subunits of the asialoglycoprotein receptor contain different sorting information. $J$ Biol Chem, 269:3277-82.

Fumoto S, Kawakami S, Ito Y, et al. 2004. Enhanced hepatocyte-selective in vivo gene expression by stabilized galactosylated liposome/plasmid DNA complex using sodium chloride for complex formation. Mol Ther, 10:719-29.

Gao S, Chen J, Xu X, et al. 2003. Galactosylated low molecular weight chitosan as DNA carrier for hepatocyte-targeting. Int $J$ Pharm, 255:57-68.

Gao S, Chen J, Dong L, et al. 2005. Targeting delivery of oligonucleotide and plasmid DNA to hepatocyte via galactosylated chitosan vector. Eur J Pharm Biopharm, 60:327-34.

Garcia L, Bunuales M, Duzgunes N, et al. 2007. Serum-resistant lipopolyplexes for gene delivery to liver tumor cells. Eur J Pharm Biopharm, 67:58-66.

Geuze HJ, Slot JW, Strous GJ, et al. 1982. Immunocytochemical localization of the receptor for asialoglycoprotein in rat liver cells. $J$ Cell Biol, 92:865-70.

Ghosh YK, Visweswariah SS, Bhattacharya S. 2000. Nature of linkage between the cationic headgroup and cholesteryl skeleton controls gene transfection efficiency. FEBS Lett, 473:341-4.

Hacein-Bey-Abina S, Von Kalle C, Schmidt M, et al. 2003. LMO2associated clonal $\mathrm{T}$-cell proliferation in two patients after gene therapy for SCID-X1. Science, 302:400-1. 
Haensler J, Szoka FC Jr. 1993. Synthesis and characterization of a trigalactosylated bisacridine compound to target DNA to hepatocytes. Bioconjug Chem, 4:85-93.

Hasegawa T, Umeda M, Matsumoto T, et al. 2004. Lactose-appended schizophyllan is a potential candidate as a hepatocyte-targeted antisense carrier. Chem Commun (Camb), 21:382-3.

Hashida M, Nishikawa M, Yamashita F, et al. 2001. Cell-specific delivery of genes with glycosylated carriers. Adv Drug Deliv Rev, 52:187-96.

Hosseinkhani H, Aoyama T, Ogawa O, et al. 2002. Liver targeting of plasmid DNA by pullulan conjugation based on metal coordination. J Control Rel, 83:287-302.

Horiuchi S, Aoyama Y. 2006. Systematic lactose-functionalization of amphiphilic octaamine macrocycle as a gene carrier. Optimization of the charge, size, toxicity, and receptor factors for hepatocyte targeting. J Control Rel, 116:107-14.

Hwang SH, Hayashi K, Takayama K, et al. 2001. Liver-targeted gene transfer into a human hepatoblastoma cell line and in vivo by sterylglucosidecontaining cationic liposomes. Gene Ther, 8:1276-80.

Illum L. 1998. Chitosan and its use as a pharmaceutical excipient. Pharm Res, 15:1326-31.

Jiang JW, Zhang Y. 2004. Targeting delivery effect of galactose receptormediated c-myc antisense oligonucleotide on human hepatocellular carcinoma cell line Bel-7402. Chinese J Cancer, 23:1288-93.

Kamruzzaman Selim KM, Ha YS, Kim SJ, et al. 2007. Surface modification of magnetite nanoparticles using lactobionic acid and their interaction with hepatocytes. Biomaterials, 28:710-16.

Karinaga R, Anada T, Minari J, et al. 2006. Galactose-PEG dual conjugation of beta-(1-3)-D-glucan schizophyllan for antisense oligonucleotides delivery to enhance the cellular uptake. Biomaterials, 27:1626-35

Kawakami S, Yamashita F, Nishikawa M, et al. 1998. Asialoglycoprotein receptor mediated gene transfer using novel galactosylated cationic liposomes Biochem Biophy Res Commun, 252:78-83.

Kawakami S, Fumoto S, Nishikawa M, et al. 2000. In vivo gene delivery to the liver using galactosylated cationic liposomes. Pharm Res, 17:306-13.

Kawakami S, Yamashita F, Nishida K, et al. 2002. Glycosylated cationic liposomes for cell-selective gene delivery. Crit Rev Ther Drug Carrier Syst, 19:171-90.

Kim TH, Park IK, Nah JW, et al. 2004. Galactosylated chitosan/DNA nanoparticles prepared using water-soluble chitosan as a gene carrier. Biomaterials, 25:3783-92.

Kim TH, Kim SI, Akaike T, et al. 2005. Synergistic effect of poly(ethylenimine) on the transfection efficiency of galactosylated chitosan/DNA complexes. J Control Rel, 105:354-66.

Kwoh DY, Coffin CC, Lollo CP, et al. 1999. Stabilization of poly-L-lysine/ DNA polyplexes for in vivo gene delivery to the liver. Biochim Biophys Acta, 1444:171-90.

Kunath K, von Harpe A, Fischer D, et al. 2003. Galactose-PEI-DNA complexes for targeted gene delivery: degree of substitution affects complex size and transfection efficiency. J Control Rel, 88:159-72.

Leclercq F, Dubertret C, Pitard B, et al. 2000. Synthesis of glycosylated polyethylenimine with reduced toxicity and high transfecting efficiency. Bioorg Med Chem Lett, 10:1233-5.

Lim DW, Yeom YI, Park TG. 2000. Poly(DMAEMA-NVP)-b-PEGgalactose as gene delivery vector for hepatocytes. Bioconjug Chem, 11:688-95.

Liu F, Park JS, Choi Y-H. 2001. Hepatocyte targeting polyethylene glycografted poly-L-lysine polymeric gene carrier. United States Patent 6177274.

Managit C, Kawakami S, Yamashita F, et al. 2005. Effect of galactose density on asialoglycoprotein receptor-mediated uptake of galactosylated liposomes. J Pharm Sci, 94:2266-75.

Mao SJ, Hou SX, He R, et al. 2005. Uptake of albumin nanoparticle surface modified with glycyrrhizin by primary cultured rat hepatocytes. World J Gastroenterol, 11:3075-9.
Martinez-Fong D, Mullersman JE, Purchio AF, et al. 1994. Nonenzymatic glycosylation of poly-L-lysine: a new tool for targeted gene delivery. Hepatology, 20:1602-8

Matsuura S, Nakada H, Sawamura T, et al. 1982. Distribution of an asialoglycoprotein receptor on rat hepatocyte cell surface. J Cell Biol, 95:864-75.

Midoux P, Mendes C, Legrand A, et al. 1993. Specific gene transfer mediated by lactosylated poly-L-lysine into hepatoma cells. Nucleic Acids Res, 21:871-8.

Mitsuru H, Shigeo T, Makiya N, et al. 1998. Targeted delivery of plasmid DNA complexed with galactosylatedpoly(L-lysine). J Control Rel, 53:301-10.

Morimoto K, Nishikawa M, Kawakami S, et al. 2003. Molecular weightdependent gene transfection activity of unmodified and galactosylated polyethyleneimine on hepatoma cells and mouse liver. Mol Ther, 7:254-61.

Murao A, Nishikawa M, Managit C, et al. 2002. Targeting efficiency of galactosylated liposomes to hepatocytes in vivo: Effect of lipid composition. Pharm Res, 19:1808-14.

Nagaoka T, Fukuda T, Yoshida S, et al. 2007. Characterization of bio-nanocapsule as a transfer vector targeting human hepatocyte carcinoma by disulfide linkage modification. J Control Rel, 118:348-56.

Nishikawa M, Huang L. 2001. Nonviral vectors in the new millennium: delivery barrier in gene transfer. Hum Gene Ther, 12:861-70.

Nishikawa M, Kawakami S, Yamashita F, et al. 2003. Glycosylated cationic liposomes for carbohydrate receptor-mediated gene transfer. Methods Enzymol, 373:384-99.

Oh ST, Rih JK, Kwon HS, et al. 1997. Lactoferrin as a gene delivery vehicle to hepatocytes. Exp Mol Med, 29:111-16.

Panyam J, Zhou WZ, Prabha S, et al. 2002. Rapid endo-lysosomal escape of poly(DL-lactide-co-glycolide) nanoparticles: implications for drug and gene delivery. FASEB J, 16:1217-26.

Park TG, Jeong JH, Kim SW. 2006. Current status of polymeric gene delivery systems. Adv Drug Deliv Rev, 58:467-86.

Park YH, Park YH, Shin BA, et al. 2000. Galactosylated chitosan - graft dextran as hepatocyte-targeting DNA carrier. J Control Rel, 69:97-108.

Park IK, Kim TH, Park YH, et al. 2001. Galactosylated chitosan-graftpoly(ethylene glycol) as hepatocyte-targeting DNA carrier. $J$ Control Rel, 76:349-62.

Park IK, Ihm JE, Park YH, et al. 2003. Galactosylated chitosan (GC)-graftpoly(vinyl pyrrolidone) (PVP) as hepatocyte-targeting DNA carrier. Preparation and physicochemical characterization of GC-graft-PVP/ DNA complex (1). J Control Rel, 86:349-59.

Pathak A, Aggarwal A, Kurupati RK, et al. 2007. Engineered polyallylamine nanoparticles for efficient in vitro transfection. Pharm Res, 24:1427-40.

Reinis M, Damková M, Korec E. 1993. Receptor-mediated transport of oligodeoxynucleotides into hepatic cells. J Virol Methods, 42:99-105.

Satoh T, Kakimoto S, Kano H, et al. 2007. In vitro gene delivery to HepG2 cells using galactosylated 6-amino-6-deoxychitosan as a DNA carrier. Carbohydr Res, 342:1427-33.

Scherphof GL, Koning G, Bartsch M, et al. 2002. Targeting liposomes and lipoplexes to cells in the liver. Cell Mol Biol Lett, 7:251-4.

Schneider DB, Sassani AB, Vassalli G, et al. 1999. Adventitial delivery minimizes the proinflammatory effects of adenoviral vectors. J Vasc Surg, 29:543-50.

Shimada K, Kamps JAAM, Regts J, et al. 1997. Biodistribution of liposomes containing synthetic galactose-terminated diacylglycerylpoly(ethyleneglycol)s. Biochimica Biophysica Acta-Biomembranes, 1326:329-41.

Sihorkar V, Vyas SP. 2001. Potential of polysaccharide anchored liposomes in drug delivery, targeting and immunization. J Pharm Pharmaceuti Sci, 4:138-58.

Stockert RJ. 1995. The asialoglycoprotein receptor: relations between structure, function and expression. Physiol Rev, 75:591-609.

Sun X, Hai L, Wu Y, et al. 2005. Targeted gene delivery to hepatoma cells using galactosylated liposome-polycation-DNA complexes (LPD). J Drug Target, 13:121-8. 
Takei Y, Maruyama A, Ferdous A, et al. 2004. Targeted gene delivery to sinusoidal endothelial cells: DNA nanoassociate bearing hyaluronanglycocalyx. FASEB J, 18:699-701.

Tanaka T, Fujishima Y, Hanano S, et al 2004. Intracellular disposition of polysaccharides in rat liver parenchymal and nonparenchymal cells. Int J Pharma, 286:9-17.

Van Rossenberg SM, Sliedregt-Bol KM, Meeuwenoord NJ, et al. 2002. Targeted lysosome disruptive elements for improvement of parenchymal liver cell-specific gene delivery. J Biol Chem, 277:45803-10.

Wall DA, Hubbard AL. 1981. Galactose-specific recognition system of mammalian liver: receptor distribution on the hepatocyte cell surface. J Cell Biol, 90:687-96.

Wang XH, Wang SQ, Wen SY, et al. 2001. The inhibitory effects of hepatocyte targeting $\mathrm{pH}$-sensitive liposome mediated phosphorothioate antisense oligonucleotide on gene expression controlled by HCV 5'NCR. Sheng Wu Gong Cheng Xue Bao, 1:626-30.

Wang J, Gao SJ, Zhang PC, et al. 2004. Polyphosphoramidate gene carriers: effect of charge group on gene transfer efficiency. Gene Ther, 11:1001-10.
Wen S-Y, Wang X-H, Lin L, et al. 2004. Preparation and property analysis of a hepatocyte targeting $\mathrm{pH}$-sensitive liposome. World J Gastroenterol, 10:244-9.

Wong SC, Wakefield D, Klein J, et al. 2006. Hepatocyte targeting of nucleic acid complexes and liposomes by a T7 phage p17 peptide. Mol Pharm, 3:386-97.

Wu J, Wu G, Zerm M.1998. The prospects of hepatic drug delivery and gene therapy. Exp Opin Invest Drug, 7:1795-817.

Yang CQ, Wang JY, He BM, et al. 2000. Glyco-poly-1-lysine is better than liposomal delivery of exogenous genes to rat of liver. World $J$ Gastroenterol, 6:526-31.

Zhang XQ, Wang XL, Zhang PC, et al. 2005. Galactosylated ternary DNA/ polyphosphoramidate nanoparticles mediate high gene transfection efficiency in hepatocytes. J Control Rel, 102:749-63. 
